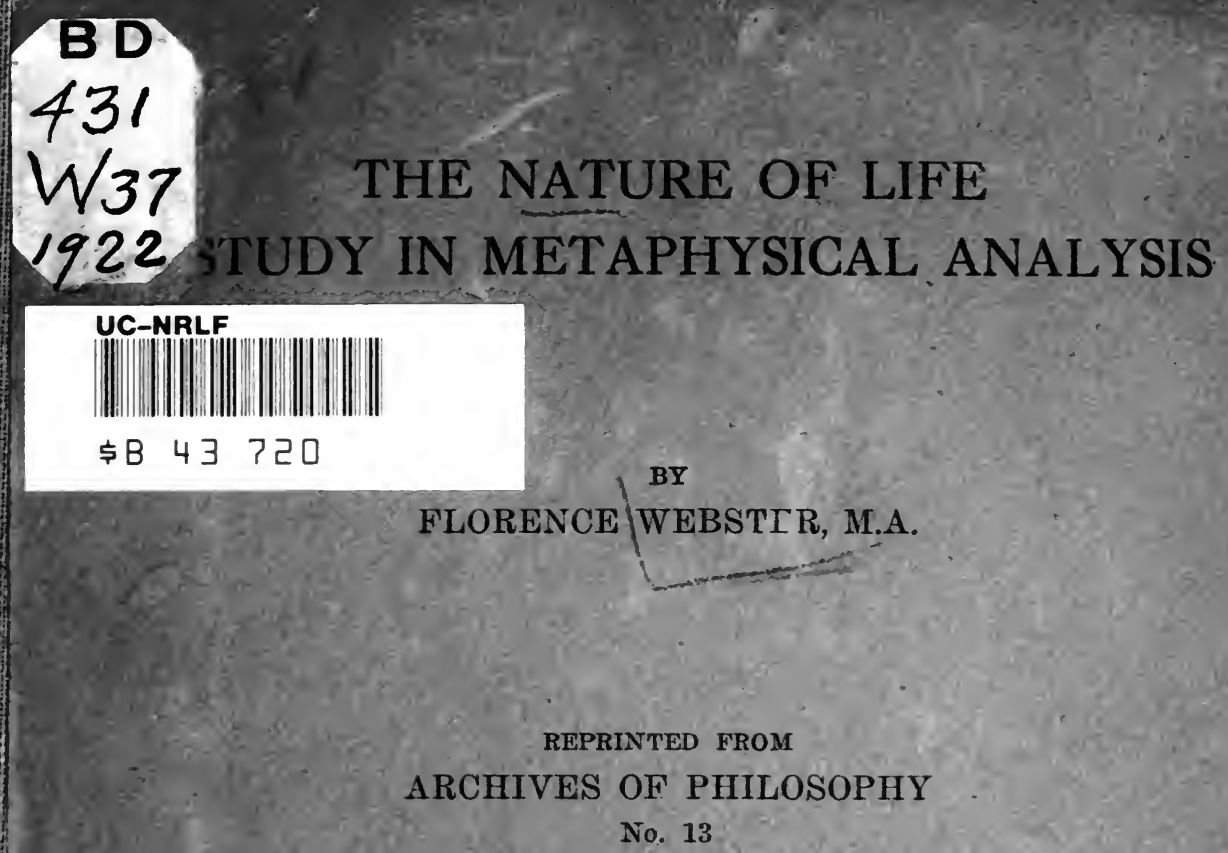

No. 13

SUBMTTTED IN PARTIAL FULFILNENT OF THE REQLTREMENTS FOR THE DEGREE OF DOCHOR OF PHLOSOPHY, IN THE FACULTY OF : PHILOSOPHY, COLUMBIA UNTVERSITY

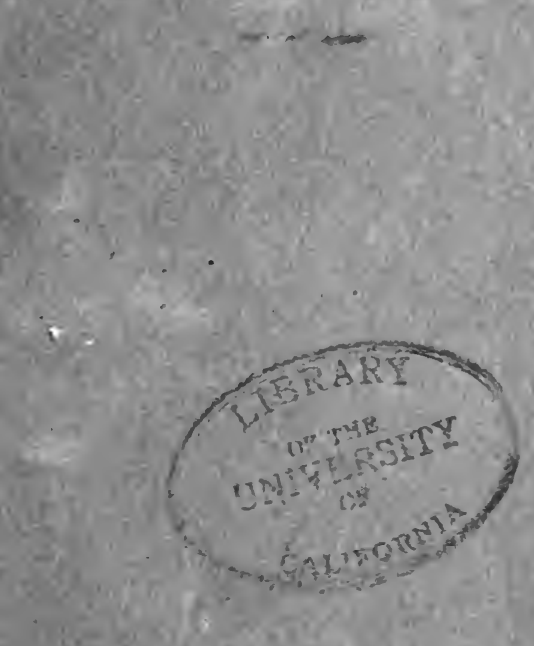




\section{EXCHANGE}
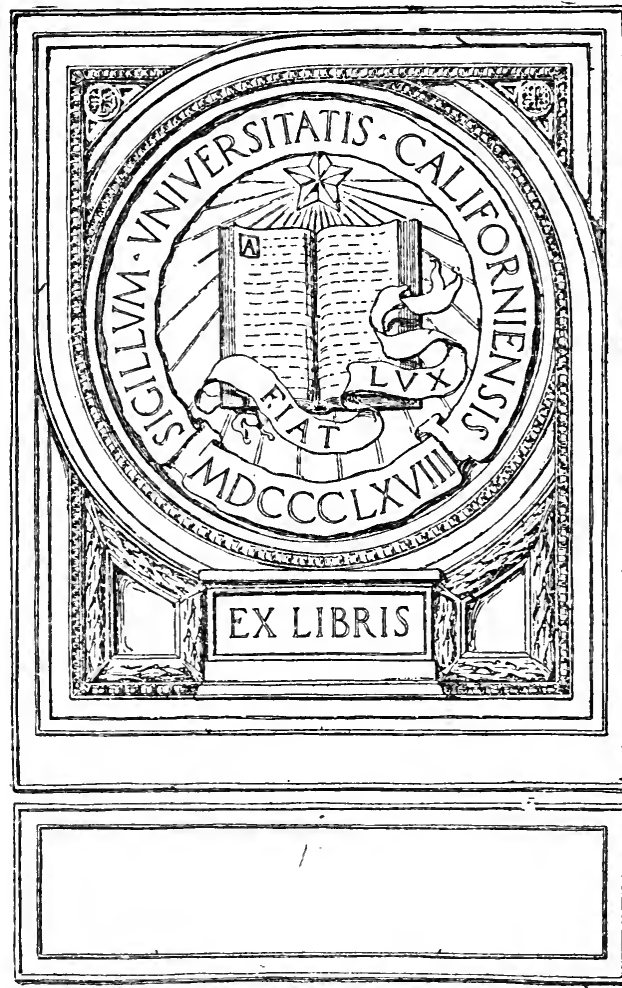


\title{
THE NATURE QF LIFE A STUDY IN METAPHYSICAL ANALYSIS
}

\author{
BY \\ FLORENCE WEBSTER, M.A. \\ il \\ REPRINTED FROM \\ ARCHIVES OF PHILOSOPHY \\ No. 13
}

SUBMITTED IN PARTIAL FULFILMENT OF THE REQUIREMENTS FOR THE DEGREE OF DOCTOR OF PHILOSOPHY. IN THF FACULTY OF PHÎOSOPHY, COLUMBIA UNIVERSITY 
$$
B D 431
$$$$
\text { W37 }
$$$$
1.922
$$

$$
\text { Exarange }
$$




\section{THE NATURE OF LIFE-A STUDY IN METAPHYSICAL}

ANALYSIS

\section{PREFATORY NOTE}

I became interested in the conception of life, while a graduate student at Wellesley in 1913. The results of my study of it at that time were embodied in a thesis, entitled "A Conception of Life," that was presented in partial fulfillment of the requirements for a master's degree at Wellesley College in November, 1914. The first section of this paper was devoted to an examination of biological conceptions of life. The second was more definitely philosophical and began with an analysis of experience, which resulted in a recognition of two contrasting aspects of reality, variously termed mind and matter, self and ideas, the spiritual and the material, the psychical and the physical, etc. Life was then defined as the imperfect union of these two.

No attempt was made to discuss in any detail the spiritual or inner life, though I felt strongly that a philosophical definition of life should cover both physical and spiritual life, as ethics and religion deal with life quite as much as biology does. I was therefore anxious to continue my study of the nature of life. However, when I returned to it in the fall of 1919, I found that life appeared in so many forms that my discussion would have to be confined to certain typical cases. These are presented in chapters II-VII of the present paper under the headings: Physical Life and Nutrition, Behavior and Sentient Life, Conscious Life and Mind, Values and the Moral Life, Life and Society, and Ideals and the Spiritual Life. The aim in each case has been to discover the fundamental characteristics of life and the basis for the differentiation of its forms.

The two papers thus agree in that they both seek to define life in such a way as to include all its forms. But they differ widely in the backgrounds against which this is worked out and in the terms used to express the results. The first paper was avowedly philosophical in a historical and critical fashion with a decided leaning toward idealism. The second is far more naturalistic and realistic and was written on the assumption that things are to be understood by discovering the structure to which they conform. ${ }^{1}$ The most familiar types or "kinds" of

1 Cf. F. J. E. Woodbridge: "Structure," Journal of Philosophy, Vol. XIV, pp. $680-688$. 
iv $\therefore \because \therefore \ldots \ldots \ldots \ldots$ IREFATORY NOTE

structure are the spatial, mechanical, chemical and logical. There appear to be temporal structures as well, as is evident in music and history for example. Life also is found to possess a temporal structure in terms of which it may significantly be defined. But unfortunately temporal structures have not been studied with the care that has been given by geometry to spatial and indeed they seem to have received very little systematic attention. Therefore I have simply attempted to indicate the temporal structure of life and suggest the relation between this and its characteristic teleological organization.

This paper, which was submitted at Columbia University in February 1921 in partial fulfillment of the requirements for the doctorate, in no sense pretends to be a complete discussion of the nature of life and is now offered rather as a suggestive study in metaphysical analysis than as a final definition of life.

F. W.

Woodstock, New YoRk,

FEBRUARY 1922. 


\section{TABLE OF CONTENTS}

Chapter

\section{INTRODUCTION}

I. The Manifold Types of Life . . . . . . . . 3

\section{EXAMINATION OF VARIOUS TYPES OF LIFE}

II. Physical Life and Nutrition . . . . . . . . 9

Chief characteristics: specific form, growth and reproduction, metabolism, and movement.

Environment : realm of mechanical and chemical structure.

Chief features or factors of physical life.

- Organization (specificity).

Temporal structure.

Teleological organization.

III. Behavior and Sentient Life . . . . . . .

Chief characteristics : behavior, sensation and emotion. Environment includes realm of primary, secondary and tertiary qualities.

Chief factors of sentient life.

Organization.

Temporal structure.

Teleology (purposive, though not purposed).

IV. Conscious Life and Mind

Characteristics: cognition and imagination.

Environment includes meaning and implication, is the domain of logical structure.

Chief factors of mental life.

Organization and individuality.

Temporal structure: prospective and retrospective aspects of consciousness.

Teleology and conscious purpose. 
V. Values and the Moral Life . . . . . . . . 42

Preliminary discussion of teleology.

Life in the realm of values or goods.

Chief factors of moral life.

Organization and character.

Temporal structure.

Teleology and design.

VI. Life and Society . . . . . . . . . . . .

Life of the individual in society.

Society as possessing a life of its own.

Chief factors of social life.

Organization.

Temporal structure (in greatly extended form).

Teleology, conscious and unconscious.

VII. Ideals and the Spiritual Life

Forms: religious, esthetic, intellectual, moral.

Realm of Ideals: the true, the good, the beautiful, God and society.

Chief factors of the spiritual life.

Organization and personality.

Temporal structure.

Teleology and ideal aims.

\section{CONCLUSION}

VIII. Definition of Life . . . . . . . . . . .

In terms of its factors:

Organization.

Temporal structure.

Teleology.

The differences in its forms due to the variety of the domains in which they occur. 


$$
\begin{aligned}
& \text { : } \vdots \because \because \vdots \quad \therefore \quad \therefore \\
& \because \therefore \therefore: \therefore \because \because \because \because \because \because
\end{aligned}
$$

\section{INTRODUCTION}




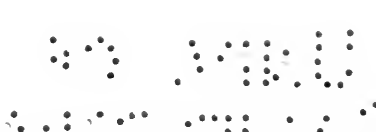

$\therefore \therefore \because \because \because \because \cdots \cdots$ 


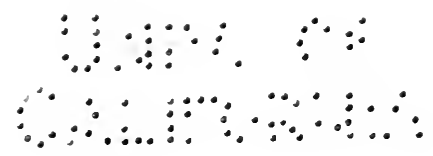

\section{CHAPTER I}

\section{THE MANIFOLD TYPES OF LIFE}

Life is at once so intimate and so general, appearing in our most personal problems and practical affairs as well as in abstract science and philosophy, that any attempt to define it seems from the outset doomed to failure. Have the biologist and the moralist anything in common when they both talk of life or are they rather using the same word with radically different meanings? Certainly Eucken's inquiries into the basis and ground of life seem to have nothing to do with the biologist's discussion of protoplasm as the basis of life; and the theologian appears to have something quite different in mind when he tries to expound the secret of life, from what interests the scientist when he considers the origin of life. In fact can there be any connection or comparison between philosophies of life such as the Stoic, Epicurean and Christian and theories of life such as mechanism and vitalism? Still these all continue to discuss life, and such contrasts as that of the speculative and practical life, of the simple and strenuous life, of rational and emotional life, of plant and animal life, and even of human and divine life are common and familiar enough, as are also such phrases as industrial, business and economic life, and collective, group and community life. But is there any significance in these all being termed life or would it be more accurate to rephrase these expressions, making the adjectives into nouns and omitting all reference to life? Doubtless this might be done in some cases, but not in all, for life, I think, has a definite meaning of its own. Intellect and practise are hardly equivalents for the intellectual and practical lives, nor business and industry for business and industrial life, and even less is the physical the same as physical life, and at the other extreme eternity appears to be quite different from the eternal life. Could Santayana's Life of Reason be called as fittingly Reason, and would Eucken's insistence on the need for the independent spiritual life have as much appeal if he left out all reference to life and talked about the need of an independent spirit? Certainly it would carry very different implications.

The differences in the types of life mentioned-and the list might be extended greatly in numerous ways--are of course important as well as evident, and it is with no intention of minimizing these that $I$ wish to suggest that these varying types are all termed life neither by accident 
nor metaphor, for $I$ think that life has a meaning that is essential to it and that occurs in these various instances and adds its content to the whole, though its contribution to the total significance of the phrases is not always recognized nor fully appreciated. It is this essential meaning of life as a universal term that $I$ hope to bring out in the present discussion and which, if found, will furnish the definition of life that I am seeking.

The search for this definition will be conducted empirically and inductively by an examination of some of the most significant types of life. The choice of instances I trust will be fairly representative and not entirely arbitrary though it does not claim to be complete. Various typical selections might be made and the forms of life classified in different ways. Plant and animal life are naturally classed as life on the biological or physical plane, while at the other extreme the moral and religious life as well as the intellectual and rational are commonly grouped together under the term spiritual, personal or inner life. Are the esthetic and sensuous, the conscious and psychical lives to be included in the same group as the religious and moral as forms of personal or inner life? And should the simple and strenuous life, business and economic life be included in the same class as well? Or should the last two be classed with national and tribal life as forms of group, community or social life? Many of these evidently have strange and often perplexing likenesses as well as differences.

In spite of this bewildering richness and variety of forms in which life appears, it seems to me that the more important kinds may be included under a few general headings, though in some cases it is difficult to find a name that adequately covers each and they show a tendency to overlap. Most clear and unequivocal appears what we may term biological life or life on the physical plane: bodily life in general whether of plants or animals, unicellular or multicellular, in lower or in higher forms - the life of organisms as the subject matter of biology. This aspect of human life is the main interest of the science of medicine and the principal concern of hygiene and sanitation. But these latter usually seem unsatisfactory if they wholly disregard the so-called higher aspects of human life, for mind and emotion often seem quite as important as nourishment and care of the body. In a somewhat similar way descriptions of animal behavior lead naturally to the use of terms that are commonly associated with mental or psychical processes. In fact a discussion of bodily life in its various manifestations seems to lead inevitably over into the realm that is commonly claimed by psychologists. We might then naturally turn from the discussion of life as presented by biology to examine it as seen by psychology. But 
THE MANIFOLD TYPES OF LIFE $: \because \vdots \because \because, \cdots, \ldots, \ldots$

here new difficulties confront us. Varied as is the subject matter of biology and its many allied sciences and much as different investigators may disagree as to the ultimate terms of explanation, there is comparatively little doubt of what they are studying, since organisms can be concretely exhibited. On the other hand the subject matter of psychology seems to be rather uncertain and doubtful. Is it consciousness or behavior, mental life or the dynamics of mind? In the text-books of psychology we find much physiology, some physics, and discussions of sensations, perceptions, instincts, emotions, thought, memory, reason, association, attention, habit, will and similar subjects - certainly a varied list. Are all these to be grouped as mental states or psychical processes and mind conceived as "an integration of coordinated psychical elements or processes-personal memories, tendencies, desires, wishes and the like" ?1 An effort seems to have been made to regard everything that is not physical, in the Newtonian sense of being expressible in terms of $m, l$, and $t$, as mental and so legitimate subject matter for psychology. But this attempt appears to fail for two quite opposite reasons: first psychologists are very much interested in many admittedly physical things, and secondly they are but little concerned with many of those aspects of life that are often termed spiritual. Of course we have psychologies of religion and of moralsin fact all forms of human activity may be treated psychologically-but it is not to such accounts that we look for accurate and vivid pictures of the religious, moral or spiritual life.

Therefore, in the interest of clearness and simplicity, I suggest that we do not attempt to consider at the same time all the forms of life with which psychology may deal. I propose indeed that in the division of our discussion we follow the lead of the material rather than that of the sciences that have treated it. We may then, after considering physical life as it appears in connection with growth and metabolism, turn to that type of life which appears as the common domain of biology and psychology and which may be roughly identified with animal life as exhibited in behavior and sensation. In other words, I propose that we first discuss vegetative or nutritive life and then sentient life. In connection with the latter the question of consciousness naturally arises and we shall devote a chapter to a consideration of mental life.

For an adequate discussion of life it would also seem necessary to consider the many attempts that have been made to interpret the meaning and value of life, for moral and religious teachers are quite as much interested in life as biologists and psychologists and indeed talk

1 H. W. Carr: "The Interaction of Mind and Body," Proceedings of the Aristotelian Society, Vol. XVIII, p. 2. 


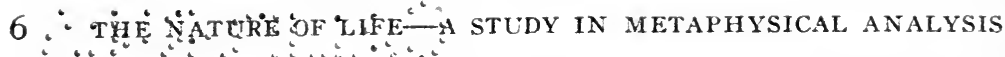

a great deal more about it. While people may be quite as much interested in their spiritual and mental health as in their bodily wellbeing, and the desire for "more abundant life" is by no means limited to physical health and vigor.

What an endless and hopeless mass of questions are suggested! Quite so; and I wish to say at once that I have no intention of attacking them all. In comparison with what might be attempted in this connection, I think that my problem may appear fairly simple and definite. though I admit that from other angles it might seem impossibly broad. But it is not my aim to attempt to decide the question of vitalism versus mechanism, nor to solve the problem of the relation of mind and body, nor pass judgment upon the rival theories of the meaning and value of life. In fact I am not setting out to explain or evaluate life but simply to define it.

With this end in view, the first thing to do is to get before us as clearly as possible the subject of our discussion. As has been already suggested, I do not wish to limit the definition to any single form or type of life but to include everything that is covered by the term, the life of the spirit as well as the life of the body, conscious and unconscious life, instinctive and intellectual life, moral and religious life, social and individual life, family and national life, etc., etc. As we evidently can not examine each of these separately, it seems best to consider some of the most typical groups of them. Therefore I propose that we begin by examining life on the biological plane, as it appears in connection with nutrition and then as exhibited in behavior, i.e. in the forms of vegetative and sentient life. We shall then devote a chapter to the consideration of mental life, instead of attempting to include sentient and mental life together as forms of conscious life or life on the psychological plane, for we have seen that psychology does not appear to furnish a clear basis for defining a type of life. After discussing life on the mental plane, we shall turn to consider life in the moral realm, follow that with an examination of social life in its varied forms, and then conclude our investigation of the various types of life by trying to get as clear a picture as possible of what may be termed the inner life or life in the spiritual domain.

In each case the aim will be to discover the fundamental factors or characteristics of life in the realm under consideration and to state these as clearly and generally as possible. We may then see in how far these agree in all cases as well as in what their differences consist and may thus arrive at the essential or fundamental meaning of life and also at the principle of the differentiation of its various forms. It should then be possible to formulate the definition of life that is the aim of the present discussion. 
Examination of Various Types of Life 
$\therefore \because \cdots \cdots \cdots$ 


\section{CHAPTER II}

\section{PHYSICAL LIFE AND NUTRITION}

Turning now to biology for an account of life on the physical plane, it is somewhat surprising to find that biologists as a rule have very little to say about life and a great deal about organisms and their various forms and functions. The taxonomist and naturalist describe the immense variety of forms in which life appears in nature, noting in what ways they resemble and differ from each other, for they aim at a comprehensive and adequate classification of all forms of life as the result of their comparative study. The embryologist on the other hand may confine his attention to the study of the development of a single type of animal, and as yet relatively few have been studied in great detail so that rather hasty generalizations have been made in this field. Still much has been done to add to our knowledge of the growth of organisms. In the branches of biology so far mentioned the main interest has been in the organism as a whole, but physiology and anatomy, as well as histology and bio-chemistry, are primarily concerned only with portions of the organism, whether these be organs, cells or chemical elements and whether interest be centered in their structures or their functions.

Before proceeding to a consideration of what biology has to teach concerning the fundamental characteristics of living matter, it may be well to note something of the great variety of organic forms in which life is here found. The distinction between plants and animals seems obvious enough and so are the more general divisions within each of these kingdoms. Flowering plants and trees are evidently different in many ways from ferns and mosses, and green plants from parasites and saprophytes such as mushrooms and fungi. In the animal kingdom the differences between vertebrate and invertebrate, between mammal, bird and fish, between insect, worm and mollusc are evident. With the added contrast of the unicellular organisms with the multicellular already mentioned, and a recognition of the great variety of microscopic life both animal and vegetable, it might seem as hopeless to try and discover the fundamental characteristics of life on the biological plane as does our more general undertaking to define life on its many planes. The difficulty of the task must be admitted in both cases, but the fact that it has often been attempted in the first may give us courage to hope that it may be accomplished in both. 
Great as is the variety of organisms, their difference from inorganic nature as it appears to the physicist and chemist would seem to be clear and unequivocal. But this difference, like that between plants and animals, it has proved difficult to formulate in such a way as to be unambiguous in all cases. Indeed there seems to be no single feature of life that can be taken as its distinctive or defining characteristic, since each that is offered turns out to be too broad or too narrow; and as a result most attempts to define biological life consist of an enumeration of some of its more prominent features. These are variously given but $I$ think that they are reducible to a few fundamental ones. Driesch says, "All living bodies are specific as to formthey 'have' a specific form, . . . exhibit metabolism; that is to say, they stand in a relation of interchange of materials with the surrounding medium, . . . and, in the last place, we can say that all living bodies move." 1 Hodge gives as the properties of life, nutrition, including all the processes of anabolism and katabolism, reproduction and growth, and irritability, including the fundamental functions of conductivity and contractibility.2 Minchin's list is the power of automatic movement exhibited by living protoplasm, amoeboid when not enclosed in an envelope and streaming when so confined as in plant cells, metabolism, i.e. anabolism and katabolism, including respiration also and resulting in growth and reproduction. ${ }^{3}$ Mitchell gives a similar list of the alleged differences between the organic and the inorganic, namely difference in structure, phenomena of movement including irritability and instability, reproduction and mode of origin, but points out that none of these are absolute and concludes that the real distinction is chemical-the presence of proteid. ${ }^{4}$ Karl Pearson in his Grammar of Science examines consciousness and the laws of motion applicable to living and lifeless matter, but finds that neither furnishes the desired distinction and he concludes that life can be defined only by secondary characteristics: the most important ones for him being the presence of protein, the method of growth by inner instead of outer addition, reproduction and the necessity of a peculiar environment with certain conditions of moisture and temperature. ${ }^{5}$ Henderson in his attempt to define life as a basis for his discussion of the "fitness of the environment," emphasizes complexity both structural and functional, metabolism which he later holds is to be con-

1 The Science and Philosophy of the Organism, Vol. I, p. 16.

2 "Living Matter" in the Baldwin Dictionary of Philosophy and Psychology.

3 "Protoplasm" in the Encyclopaedia Britannica, IIth ed.

4 "Life" in the Encyclopaedia Britannica, IIth ed.

s Second edition, London, Black, 1900, pp. 338-345. 
ceived in terms of equilibrium, and regulation which is later reduced to organization. ${ }^{6}$ Schäfer emphasizes the importance of the coordination of parts and the due regulation of their activity in the maintenance of life, ${ }^{7}$ "while Troland says "regulation seems to be the most striking active characteristic of living beings." 8

Many other similar lists of the important characteristics of living organisms could be given, but they would in general merely repeat in different ways the features already noted. Much repetition is obvious even in the few examples given, though these were chosen with a view to showing as much variety as possible. Indeed it seems to me that the chief features of biological life fall into four main groups: the first of which may be described as specific form and complexity of structure, the second as development covering growth and reproduction, the third as metabolism or nutrition and including respiration. and the fourth as movement. Such characteristics as organization and regulation are found in connection with these and will appear in the discussion (description and analysis) of the four characteristics just mentioned which I now propose to consider in greater detail.

When plants as well as animals are considered, specific form or structure is perhaps the most obvious characteristic of organisms. It furnishes the chief basis for biological classification and has been particularly emphasized in the descriptions given of organisms by taxonomist and naturalist. The immense variety and wealth of organic forms has already been mentioned and is so evident that there is little need of considering it in detail, but it is worth while, I think, to note that definite and complex structure is not limited to multicellular organisms. The structure of plants and animals is so commonly thought of in terms of organs and tissues composed of cells, that there is a tendency to regard the cell itself as simple and structureless. But the study of one-celled animals (the protozoa) shows that they possess definite and specific structure comparable in complexity and function to that of the metazoa, and Ritter maintains that definite organs and tissues are discoverable, which can be denied these names only by so defining them as to require that they be composed of cells. ${ }^{9}$ Though less is known about the structure of bacteria, they are by no means formless, as is evident from the fact that so many varieties of them

- The Fitness of the Environment, New York, Macmillan, 1913, pp. 30-35. Cf. The Order of Nature, Cambridge, Harvard University Press, 1917, pp. 80-84. "The Nature, Origin and Maintenance of Life," Scicntific American Supplement, Vol. LXXIV, p. 227.

8 "The Chemical Origin and Regulation of Life," Monist, Vol. 24, p. 96.

The Unity of the Organism, Boston, Badger, 1919, Vol. I. p. 240. 
pising $x^{2}$

are recognizable under the microscope. Embryology and histology have also emphasized the variety and complexity of cell structure, ${ }^{10}$ especially in the case of ova and spermatazoa, and also their specificity for each species. For not only are the adult forms of each species true to type. but so also are all forms of the organism from germ cell to adult. Careful microscopic observation shows that seeds and eggs are specific and typical, while we all know that acorns develop into oaks and not elms or cabbages and that chickens are hatched from hens' and not turtles' eggs. The eggs of our wild birds differ about as much as do the birds themselves and careful study reveals specific differences in the eggs of fish of different varieties. The same specificity of form is found throughout the growth of each individual. This is particularly impressive in cases where there are intermediate forms quite different from the mature organism: the caterpillar and butterfly, tadpole and frog, larva and mosquito are perhaps the most familiar examples, while the descriptions given of the development of sea-urchins and other simple forms of marine life show it quite as clearly. Indeed specific form is not merely a characteristic of the adult but extends over the entire life history of the organism. Thus "the living form may be called a 'genetic form' or a form considered as a process," 11 for it is a temporal as well as a spatial affair and in fact it seems to be its temporal rather than its spatial aspect that distinguishes the specific form of organic life from other physical objects. This would seem to be the reason why attempts to define the specific form characteristic of living beings in merely spatial terms have failed to distinguish them from other physical structures such as crystals and certain liquids and colloids. It has, of course, been customary to point out the greater complexity of their parts, their closer inter-relatedness and more perfect integration and organization. But though these latter categories are important in any consideration of life, they do not appear to be adequate for a description of specific form, as this can be understood only in connection with the life histories of the organisms under consideration. In fact, so far as organic life is physical it conforms to the mechanical structure of its environment, and thus it is not possible to differentiate organisms from other physical objects in merely mechanical and spatial terms. For it is in their relation to time rather than to space that they differ from their inorganic environment, since their specific forms are worked out only through temporal processes and develop according to specific patterns

$10 \mathrm{Cf}$. E. B. Wilson: The Cell in Development and Inheritance. New York, Macmillan, 1900.

11 Driesch: Loc. cit., Vol. I, p. 20. 
in time as well as in space. They thus possess temporal as well as spatial and mechanical structure and in fact their characteristic differences seem to be due to the former rather than to the latter.

The case appears to be very much the same when we turn to consider the chemical composition of living matter. For, though chemical analysis is constantly adding to our knowledge of the composition of protoplasm and the list of elements found in it seems to increase with more accurate methods of investigation, no element peculiar to living matter has been found, so that the difference between organic and inorganic matter is apparently due to its. organization or structure rather than to its elements. Of organic compounds the most common are carbohydrates, fats and proteins, and the latter are especially emphasized in discussions of life as they are the most complex and characteristic. Loeb points out that they differ for different genera and even for different species of the same genus, ${ }^{12}$ and that they may even show family and individual differences is suggested by experience with blood transfusions. Thus not only is there no discoverable living element, but the chemical structure of protoplasm varies with different genera so that Ritter maintains that the term should be used in the plural-protoplasms-rather than in the singular. ${ }^{13}$ Thus the specificity so characteristic of organisms is seen to hold for their chemical composition. But it is not to be attributed to unique living elements, for organic matter is made up of the same chemical elements that are found elsewhere in the physical world. The difference is rather the result of the method of their composition which appears to be a temporal as well as a chemical affair-living compounds being produced only from other living forms. It is thus the temporal factor which appears to be at the bottom of the difficulty of synthesizing living matter in the laboratory. The chemical elements can be brought together in the right proportions but the temporal pattern can not be compressed into the comparatively short time at the scientist's disposal. That is, the structure of protoplasm is temporal as well as chemical and this is true both of living matter in general and of each individual form. Thus if we are to understand the nature of living matter we must take account of both the long history of life upon the earth and the specific life histories of the forms under consideration.

This is further emphasized by the facts of heredity, however much confusion may be caused by the various theories upon the subject. If Castle's definition, which Ritter commends so strongly because of "its non-commitment to any theory" (i.e. "by heredity, then, we mean

12 The Organism as a Whole, New York, Putnam. 1916, p. 68.

13 Loc. cit., Vol. I, p. I48. 
organic resemblance based on descent" $)^{14}$ be accepted, it appears to be but one way of expressing the relation of individual to species that may be described from another point of view in terms of reproduction. In either case the important thing to note is that the specific form (and function as well for that matter) of the species is maintained through a succession of individuals, each of which develops "in accordance with a scheme or pattern characteristic of the species to which the organism belongs, so that any particular individual in the series resembles those which have gone before it." 15 This by no means excludes variation, which is also characteristic of organic development and must be reckoned with as a fact however it may or may not be explained by the theories of heredity.

In all development then, whether it be individual growth or reproduction, there is continuity in the midst of change. In some of the most familiar cases of animal growth this appears as the maintenance of specific form amid slowly but constantly changing matter, but a study of the development of any individual from germ to adult shows changes in form as well as in matter, while the fact that all organisms arise from other organisms emphasizes the material continuity of life. This brings the temporal nature of life to our attention again and suggests the wide range of temporal structure, the importance of which has already appeared in our examination of the specific form of organisms. In fact development and form are seen to be very closely related, since the specific form of an individual can only be understood by reference to its inheritance and growth, while development proceeds specifically and produces characteristic forms at all stages and can only be understood in connection with these. The temporal structure characteristic of life thus possesses definite direction.

As for the mechanism of reproduction and growth much is surmised and comparatively little is known. There seems to be a correlation hetween the chromosomes of the germ and certain definite characteristics of the adult forms, but the cytoplasm as well as the nucleus would seem to be important in determining development and the germ though a single cell is far from structureless. But this does not necessarily mean that it contains a preformation of the organism that is to develop from it, which, indeed, in view of the great complexity and variety of forms that often intervene would seem quite impossible.16 But fortunately it is not necessary for the present purpose of definition

${ }^{14}$ Loc. cit., Vol. I, p. 315.

15 Ibid., Vol. I, p. 322.

16 Cf. E. B. Wilson: "The Problem of Development," Science, N. S. 2I, PP. $28 \mathrm{I}-294$. 
to explain all the phenomena of life, so the problem of epigenesis versus preformation and evolution may be left to the biologists to decide by observation or theory as best they can.

The process of growth proceeds by differentiation and integration or organization. With the metazoa this is closely connected with cell division, the organism arising from a single germ cell by a process of successive divisions that result in the differentiation of the cells of the various tissues together with their organization or integration into organs and the organism as a whole. Of course differentiation and integration proceed together: the germ is the organism as a whole in a one-celled stage and throughout the process of development the organism always exists as a whole but it is constantly becoming more complex as its tissues and organs become differentiated, but it remains a single -whole throughout, as its organization keeps pace with the differentiation. With the protozoa all individual growth is confined to a single cell, though this may be described in terms of differentiation and organization as these tiny animals possess a complex structure comparable to the tissues and organs of the higher forms. Here celldivision means reproduction; and in a similar sense most of the growth of multicellular organisms can be described as reproduction since it proceeds by cell division while what in these cases is specifically called reproduction may be regarded as a special instance of their growth. The mechanism by which this is brought about becomes increasingly complicated especially in the case of sexual reproduction, but the great interest in this latter form should not blind us to the essential similarity of the process in all cases.

All growth and development proceeds upon the basis of metabolism. which in fact is sometimes regarded as the fundamental characteristic of life and especially of the life of the cell. In this broad sense metabolism may be regarded as covering nutrition and respiration as well. It is customary to distinguish anabolic from katabolic processes as respectively constructive and destructive. In general anabolism may be regarded as including the absorption of food-stuffs which are obtained from the environment both organic and inorganic and the conversion of this material into the organic compounds characteristic of the organism, thus making possible both growth and repair within the living body. Katabolism, on the other hand, covers the breaking down of organic compounds with the liberation of energy. Neither process is entirely synthetic or analytic in the chemical sense, since all organic compounds that are taken in as food are broken down into simpler complexes before they are finally synthesized into compounds characteristic of the organism employing them, while the fact that synthetic 
processes accompany the analytic in katabolism is apparent in the neutralization of certain poisonous products resulting from the dissociations characteristic of katabolism. Chemically at least the metabolism of plants appears to be radically different from that of animals, as is evident from the different rôles played by oxygen and carbon dioxide in the two cases and the fact that green plants can utilize inorganic material to an extent that is impossible for colorless plants and animals. Certain micro-organisms seem to possess different chemical powers from either plants or animals: $:^{17}$ an important example being the power possessed by the nodule bacteria, found in the roots of leguminous plants, of fixing the free nitrogen of the air so that it is available for the use of plants, while other forms of bacteria liberate the nitrogen in dead organic compounds so that it is again utilizable. ${ }^{18}$

But it is with the general characteristics of metabolism rather than the details of its mechanism that we are at present concerned. In this connection it is to be noted that all organisms are capable of taking materials from their environment and building these into their own structure. This is accomplished by a process of dissociation and reintegration, as compounds are broken down into simpler substances before being absorbed and built up into the tissue of the organism. The resulting compounds are probably specific in chemical composition ${ }^{19}$ and it is certainly through this metabolic process that the specific form of the organism is developed and maintained. In this sense metabolism as well as growth may be regarded as teleological if this means that a definite end is attained through a variety of means ${ }^{20}$ or that the individuality of the whole is maintained through constantly changing matter, or if "all processes leading to factual wholeness" are regarded as teleological. ${ }^{21}$ Each of these expressions is inadequate and in some ways objectionable and we shall later examine in greater detail the meaning of teleology, so that all I wish to do here is to call attention to the fact that organic development is in a sense teleological. The teleology here apparent is evidently closely connected with the tendency of organisms to develop in definite ways: that is, it is to be understood in terms of tendency and direction and so seems to be closely related

17 Cf. J. Johnstone : Press, 1914, pp. $267 \mathrm{ff}$.

The Philosophy of Biology, Cambridge, University

$18 C f$. E. O. Jordan: General Bacteriology, Philadelphia and London, Saunders, I918, Chapter 34.

${ }^{19} \mathrm{Cf}$. J. Loeb: Loc. cit., Chapter III.

${ }^{20}$ Cf. E. A. Singer, Jr.: "The Pulse of Life," Journal of Philosophy, Vol. $\mathrm{XI}$, pp. 648-649.

$21 \mathrm{H}$. Driesch: The Problem of Individuality, London, Macmillan, 1914, p. 3. 
to the temporal structure that we have seen to be characteristic of living beings.

As the anabolic processes furnish the basis for the development and growth of organisms, so the katabolic appear as the foundation of their activity and movement. Reference has already been made to the amoeboid and automatic movements that are said to be characteristic of protoplasm in all its forms. As I propose to consider behavior in conneçtion with sentient life, we may here simply note the fact that irritability, conductivity and contractibility are characteristic of all protoplasm and may be regarded as the basis of all types of behavior, while we shall reserve a detailed discussion of behavior for the next chapter. This is admittedly a limitation of the biological conception of life which may appear arbitrary to many biologists. But as has already been suggested, my present interest is in the description and analysis of the nature of life as it appears in many different realms and connections. In each case my aim is to get as clear a view of life as possible, while my interest in defining the different domains themselves is decidedly secondary. It is not my purpose to dictate to biologist or psychologist what they should study nor what the relations between them should be, but to go to them for a description of life as they see it. But as psychology does not seem to present a single definite picture of conscious life, but rather a confused variety, it has seemed better for our present inquiry to consider sentient life, as characterized by behavior and sensation, as distinct from mental life. Since the first interests both biologists and psychologists and their treatments of it overlap to a considerable extent, as they both deal with the same material and differ rather in their presuppositions and explanations than in the facts with which they are concerned, I have chosen to consider this common field separately rather than to assign it to either.

Our examination of the characteristic features of living organisms has, I think, shown the important factors of life on the biological or physical plane. First, the biologist emphasizes the fact that he deals with life only as it is found in connection with matter, for the question of disembodied life has no interest for him. Life here then possesses spatial and mechanical and also chemical structure. It is this aspect of life that seems all important to biological mechanists and they therefore hope to be able finally to explain all life phenomena completely in physico-chemical terms. Such a hope may seem to be supported by the fact that chemical analysis reveals no new element peculiar to living matter and that organisms possess no unique mechanical structure. This is hardly to be wondered at since living organisms maintain themselves in a physico-chemical environment upon which they depend for 
the material required for their development. They thus show a certain continuity with their environment as well as among their own forms. But if physical life were indistinguishable from its mechanical environment, we might as well abandon the term life in this connection and confess that we were dealing with only the physical. The mechanists however are hardly willing to go so far as that and usually admit that life possesses a peculiar structure of its own. Chemically this may be expressed by saying that protoplasm and protein are peculiar to organic matter, not in the sense that they can not be analyzed into simpler inorganic elements, but rather that they have not been synthesized from these elements. Of course many compounds that were once regarded as organic because they were found only in connection with organisms have now been synthesized in the laboratory, and chemists may hope sometime to do the same with the higher organic compounds. However that may be, certain chemical compounds do not seem to occur in nature apart from organic matter, though their distinction from inorganic compounds is not expressible in terms of the chemical elements which they contain, but is rather a function of the peculiar architecture of the mixtures due to their long history as well as to their high complexity. ${ }^{22}$ "In other words, the present physical and chemical structure of organisms must be explained not only in terms of atoms and molecules but also in terms of the history of living matter upon the earth." 23 In fact, as we have seen, life is characterized by its temporal rather than by its mechanical and chemical structure.

Its temporal structure was also emphasized by our consideration of organic development. Here, as in connection with chemical composition and specific form, the historical aspect is usually most stressed, but as has already been suggested a future reference is involved as well. An acorn is not only the result of its past but may also be said to hold its future "in suspension." An attempt to understand life. then, seems to necessitate a consideration of the nature of temporal structure and an investigation of some of its more important "kinds."

To be noted first is the difference between time as it appears in mechanics and in biology. The former may be called physical or mathematical time and appears as a succession of instants which are only externally related, and is thus essentially atomic. Like space, it may be regarded as a type of separation or mode of extension and may be described as a univeral form of connection whose elements are accordingly indistinguishable in themselves and so devoid of indi-

22 P. C. Mittchell: "Life," Encyclopaedia Britannica, IIth ed.

23 Comstock and Troland: The Nature of Matter and Electricity, New York, Van Nostrand, 1917, p. 194. 
viduality. It may then be regarded as analogous with space or even as a fourth dimension of space. In this sense time appears an an independent variable in the differential equations of mechanics. Here its direction is unimportant and the distinction between past and future is lost and the time sequence may be regarded as reversible or repeatable. This time, "flowing equably in measurable lapses"24 and "measured in terms of simultaneous displacements," 25 is by no means identical with the temporal structure to which biology directs attention, and in fact even in chemistry there appears to be "successive or genuinely temporal displacements" which seem to indicate the existence of essentially temporal structures. ${ }^{25}$ And the importance of history in such physical sciences as geology for example in its explanation of the formation of strata, seems to assign to time a rôle quite different from that played by it in mechanics. In these last cases we seem really to have something that may be described as simple temporal structure characterized by succession and direction, but in other respects resembling physical and mathematical time.

But the temporal structure that appears to be characteristic of life on the biological plane is still more complicated and less like the time of mechanics. Whitehead conceives it as rhythm which involves a pattern that differs somewhat in each exhibition, since "the essence of rhythm is the fusion of sameness and novelty; so that the whole never loses the essential unity of the pattern, while the parts exhibit the contrast arising from the novelty of their detail."26 Certainly many life processes are obviously rhythmic, so that life without doubt possesses a rhythmic temporal structure, but this seems hardly to be the distinguishing feature of life as molecules and solar systems also exhibit rhythm and it is an essential feature of music as well. Here the unit is no longer the instant of mathematical time but rather an appreciable duration that possesses a pattern within itself so that "the more perfect rhythm is built upon component rhythms," 26 and the present is no mathematical instant, but in Royce's words a "time span" of greater or lesser length, and is not to be conceived as the sum of a definite number of instants any more than a line is constructed from a certain number of mathematical points. ${ }^{27}$ Rhythmical or musical time then seems to possess direction and to consist of unique and individual

24 A. N. Whitehead: An Enquiry Concerning the Principles of Naturai Knowledge, Cambridge, University Press, 1919, p. I.

25 F. J. E. Woodbridge: "Structure," Journal of Philosophy, Vol. XIV. p. $68 \mathrm{r}$.

26 Loc. cit., p. 198.

27 Cf. E. G. Spaulding: The Nerv Rationalism, New York, Holt, 1918, pp. $45 \mathrm{I}-454$. 
elements, in such a way as to render it irreversible but not irrepeatable, for a certain repetition, albeit with variation, seems essential for rhythm.

Bergson's discussion of duration comes nearer to characterizing the temporal structure that our examination has suggested as an important factor in the conception of life. This he sharply contrasts with mathematical or spatialized time, as an intensive in contrast to an extensive manifold. Its elements are unique and individual, yet interpenetrate, that is they may be said to be internally rather than externally related, and form irreversible and non-repeatable series. ${ }^{28}$ Though such a statement leaves much to be desired in the way of clearness and precision, it is highly suggestive, I think, as pointing out the immense difference between time as it appears in the mechanical and in the biological realm, and so helps to free us from the domination of the former in our investigations of the latter. Here time as duration does not appear to be homogeneous and amorphous, but to possess a definite structure describable in terms of differentiation and integration, of organization and direction.

Sketchy as the preceding discussion of time has been, I think that it suggests the possibility of a great variety of temporal structures. The description of time as one-dimensional with the implied comparison of it with a line, whose most essential characteristic is its division into two parts, past and future, by a point called the present would seem to very strictly limit or even to exclude the possibility of variety of temporal structure. But the difficulty here seems to be due to the comparison of time with a line rather than to the fact that it is regarded as one-dimensional, for the great variety of series, including discrete, denumerable, dense and continuous, suggests that variety of structure is not dependent upon multiple dimensionality. While the possible wealth of temporal structure may perhaps be suggested if it is recalled that the third dimension of space, though describable as an added axis to the coördinates of a plane, makes possible a complexity of structure in three dimensions that would be quite inconceivable to a two-dimensional creature. For example, a circle may be the cross-section of a sphere, cylinder or cone, while each of these may have ellipses as crosssections as well. Thus if time were to be conceived as a fourth dimension, it would be most inapt to call it a line unless our three-dimensional space were then regarded as a single point of that line. It would seem that in a sense mechanics can do this, though in thus assimilating

28 See Creative Evolution, trans. by Mitchell, New York, Holt, I91 I, pp. I-23. Also Time and Free Will, trans. by Pogson, New York, Macmillan, 1912, Chapter II. 
time to space it appears to limit itself to a special type of temporal structure and to disregard all others. To refer to the preceding example, extension in time as commonly conceived has an effect analogous to that which gives a cylinder when a circle is extended into three dimensions, the other possible structures such as the sphere and cone of which the circle may be the two-dimensional representative being wholly disregarded. In other words, in regarding time as a fourth dimension, it is frequently conceived as simply extending spatial structures in a new direction in the way in which a cylinder may be regarded as a circle pulled out into three dimensions, and the immense increase in variety and complexity of structure that it would make possible seems to have been overlooked.

In fact it would seem that temporal structure has received little consideration for itself, but rather has been dominated by the practical concerns of men. This may account for the predominant place assigned to the present and the feeling that what temporal structure there is must be historical and in some way condensed into the present. It is true that the here-and-now is the position of our effective action, that the past appears to us as the irrevocable and the future as the realm of possibility, but we can no more act in all parts of space than in all parts of time and I wish to suggest that temporal structures are not to be necessarily expressed in terms of past, present and future, any more than spatial structures are in those of right and left, front and back, up and down with reference to ourselves. In other words, I am urging that temporal structure like spatial structure is not dependent upon particular existences, but is rather a principle to which they conform. If this is the case, temporal as well as spatial structures and the formulae of mathematics would seem to belong to what the neorealists term the subsistential in contrast to the existential realm or in Platonic terminology to the realm of ideas or essences. The future then as well as the past would be included in temporal structures in the same sense that the distant is in spatial, which evidently means that both distinctions are due to our interests and position and not inherent in the structures themselves. Of course this is not to be taken as implying that the future course of existence is predetermined, for all structure is inert and no causal efficacy is to be attributed to it. ${ }^{29}$ But important as efficient causes are in controlling all things, they are by no means adequate for our understanding of the universe or ourselves, since an inquiry into the "reasons why" includes the "in order that" or "for what" as well as the "because," and purposes as well as causes

29 Cf. Woodbridge : Loc. cit., p. 688. 
have to be considered. We are thus naturally led to a consideration of teleology.

The contrast of the teleological and mechanical is often expressed as that between efficient and final causes, when it is easy to make teleology appear ridiculous as maintaining that a non-existent future can produce something in the present. But if our analysis of temporal structure is correct, this contradiction does not arise unless we attempt to treat teleology mechanistically, which inevitably leads to confusion as it involves an abandonment of the distinction with which we were operating. As teleology is commonly discussed in terms of purpose or value, anything like an adequate examination of it will naturally be deferred until we have considered some of the other forms of life in which it is more prominent. Here we shall only note the form in which it appears in biological life. Organic growth and development are teleological in the sense that specific ends are attained through a variety of means $\mathrm{s}^{30}$ or that "a great many of the processes occurring in the organism bring about this wholeness, or restore it if it is disturbed in any way." 31 This would seem to imply a close relation between teleology and organization, coördination and regulation and Henderson's examination of fitness and adaptation apparently leads to the same result. ${ }^{32}$ So far then as biology is concerned, if reference to consciousness be excluded, teleology seems to be closely connected with the temporal structure and organization characteristic of life. But it is equally true that the organization characteristic of biological life may be defined in terms of teleology and temporal structure, while an adequate description of the latter seems to require reference to both teleology and organization.

In fact organization seems to be a very important feature of biological life. Indeed it is so common and general a characteristic of organisms that it is expressed by quite a variety of terms according to the emphasis and context in which it occurs. Thus we speak of the integration, coördination, correlation and regulation of life processes and in its more static aspect we describe it as a complex system, "creative synthesis" or organic whole, and refer to its structure, spatial and temporal. Different as are some of the connotations of these terms. they all seem to emphasize a fundamental characteristic of organic life that implies a certain relational unity and durability based on multiplicity and complexity. This may suggest Singer's comparison of life to a wave moving freely through an ocean of mechanism, ${ }^{33}$ which

${ }^{30}$ Cf. Singer: Loc. cit., pp. 648, 649.

$31 \mathrm{H}$. Driesch: Problem of Individuality, p. 3.

32 Cf. The Order of Nature, pp. $204 \mathrm{ff}$.

33 Loc. cit., p. 650. 
brings us back again to the dependence of life upon mechanism as evident by its physico-chemical basis and environment.

The characteristic factors of life as it appears on the biological plane-namely its mechanical basis, temporal structure, organization and teleological aspect-then seem to be closely interrelated, at least so far as they appear as the features of life, though each in itself may be definable apart from the others and from life. Certainly mechanism can be so treated and probably some forms of temporal structure. At the other extreme teleology may be regarded as independent of the others, while organization appears to be most dependent upon the rest. Our analysis therefore can not claim to have reached the ultimate or simple elements of life, but I hope that it has proceeded far enough to show certain important features in terms of which life may be significantly defined. If this be admitted, life on the biological plane implies a mechanical basis, temporal structure and teleological organization. 


\section{CHAPTER III}

\section{BEHAVIOR AND SENTIENT LIFE}

As we found it convenient to limit our discussion of biological life in the preceding chapter to its metabolic aspects, omitting any examination of behavior, we have now to consider that aspect of life which is treated by both biologists and psychologists. It may well be termed sentient life. We approached it in the last chapter in connection with movement, and might there have considered tropisms and reflex and instinctive actions, but this would have naturally led to a discussion of habit and learning, of acquired and of voluntary actions and so have carried us over into the domain commonly assigned to psychology. It therefore seemed wise first to consider physical life as expressed by the growth and development of specific forms through metabolic processes. As this is the most evident aspect of plant life, it may be termed vegetative life or described as nutritive life, as nutrition is its most marked feature, or it might be called physical and chemical life as it is dependent upon and conforms to the physical and chemical structure of its surroundings. With animal life other aspects of the environment become important, for animals react to many qualitative differences. We have therefore to consider sentient life and, making use of whatever biologists and psychologists have to offer in this connection and avoiding questions of explanation, endeavor to get as clear a picture of the facts as possible. Therefore let us try to approach our material without presuppositions and not trouble ourselves with such puzzles as those of the objective and the subjective, the possible criteria of consciousness, or such questions as whether animals or even other men have minds. We are concerned neither with why things are as they are nor how it is possible for them to be so, but desire simply to find out what they are in so far as that will throw light on the nature of life.

Turning then to an examination of organic behavior, we may first note that it extends over a wide range and differs greatly in complexity and variety, as might be expected from the great number of different forms of organisms. Though movement and behavior are of course most obvious in animal life, they are also evident in some forms at least of plant life and there would seem to be less difference between the behavior of certain plants and some of the lower animals than between the latter and higher animals: thus the heliotropism of 
certain sessile animals very closely resembles that of plants, while the movement of certain motile plant forms is very like the behavior of some of the lower animals. ${ }^{1}$ In this respect as in many others there seems to be no sharp break between plant and animal life. Though it is natural to contrast these simple forms of behavior with that of the higher animals and especially with human behavior, it none the less seems impossible to find a clear dividing line between them. This is only what might be expected if the continuity of animal life is accepted. As we attempted in the last chapter to consider biological or physical life as exhibited in nutrition and growth in all its varied forms of plant and animal, unicellular and multicellular, so we now propose to make our examination of organic behavior as wide and inclusive.

Jennings has given us illuminating accounts of the behavior of some of the lower organisms, including amoeba, paramecium and other forms of protozoa as well as a few of the metazoa. ${ }^{2}$ Loeb's discussions of tropisms contain descriptions of plant as well as of animal behavior. Animal psychology has been collecting great masses of material concerning the behavior of animals of various types, including rats, guinea pigs, dogs, monkeys, etc., ${ }^{3}$ while behavioristic psychology treats human behavior after the same fashion and would leave out all reference to consciousness. For the present I propose to follow this lead and consider behavior as an organic process and postpone the discussion of consciousness. This does not necessarily imply that we must consider that all behavior is purely and completely mechanical, for we have already seen that biological life can not be fully expressed in mechanical terms. The world is not so simple that the unconscious is necessarily mechanical. Further we have seen that teleology does not appear to be dependent upon consciousness and that teleology and mechanism need not be contradictory. In fact teleological processes may move through a mechanical world or conform to mechanical structure, and causes and uses appear to be categories of different levels and so may be applied to the same things without contradiction.

As before, our interests lie in description and analysis, not in explanation. Jennings in describing "the daily life of paramecium"

1 Cf. J. Loeb: The Mechanistic Conception of Life, Chicago, University Press, 1912, pp. 28, 29. Also his Studies in General Physiology. Chicago, University Press, 1905, Chapter I.

${ }^{2}$ H. S. Jennings: Behavior of the Lower Organisms, New York, Columbia University Press, 1906.

3 See M. F. Washburn: The Animal Mind, New York, Macmillan, 1917, for some brief accounts of results, and especially for a list of titles dealing with the subject. 
says "the animal swims about, continually hesitating as it reaches regions where conditions differ, trying new directions, and changing its course frequently. Every faint influence in the water affects it, for the animal is very sensitive." "Its behavior is in principle much like that of a blind and deaf person, or one that feels his way about in the dark. It is a continual process of proving all things and holding to that which is good."' 5 Its movements are of course limited by its structure, and its "action system" includes only a small number of lefinite movements. With greater complexity of structure, a greater variety of actions becomes possible and the higher animals possess very complicated mechanisms of response.

As we have already had occasion to note, the protozoa are by no means structureless, and even the amoeba, which Jennings describes as a "simple naked mass of protoplasm," "reacts to all classes of stimuli to which higher animals react (if we consider auditory stimulation merely a special case of mechanical stimulation)."' In the higher forms of life we find definite organs developed to perform the various functions that in the simpler seem to be characteristic of protoplasm. Thus the higher animals possess sense organs, nervous system and muscles which coöperate to bring about the response to stimuli that is characteristic of behavior. These structures, of course, vary greatly in complexity with different types or grades of animals, but their function and principle seem to be the same throughout. The sense organs become differentiated to correspond with specific qualitative differences in the environment which affect the organism, while the function of the nervous system is not only conduction as is commonly stated, but also integration, as Sherrington has pointed out. ${ }^{7}$

Various types of action thus become possible and we find behavior lescribed as reflex, instinctive, habitual, learned, intelligent, purposive, etc. These distinctions evidently rest on different bases and some imply the contrast between conscious and unconscious action. Reflex action is considered the simplest type and in diagram form the specific stimulation of a sense organ is supposed to bring about a definite reaction quite automatically, as the "spinal frog" wipes off acid or we wink when something moves near our eyes. This is evidently dependent upon the sensitivity of the receptor organs and indeed all organic behavior seems to be dependent upon the sensibility of the organism. Thus behavior seems to indicate unequivocally the fact of sensation.

1 Loc. cit., pp. 104, 105.

5 Ibid., p. 107.

B Ibid., p. I9.

'The Integrative Action of the Nervous System, New York, Scribner's, 1906. 
The sensibility of organisms doubtless varies greatly in range with the differences in their structure and "action systems." Though the lower animals react to all types of stimuli, their reactions vary so little that it seems likely that they only discriminate between edible and inedible substances, possessing what is sometimes called the chemical sense. ${ }^{8}$ They, of course, react to mechanical contact, though not always in the same way, and their avoidance reactions may be connected with a sense of pain or unpleasantness rather than with definite sense qualities. With the development and differentiation of sense organs, the chemical sense is developed into those of taste and smell. With the development of ears, sound becomes differentiated from mechanical contact and finally tones are distinguished from noises. Many animals and plants are sensitive to changes in the direction or intensity of light and the development of eyes of increasing complexity of structure makes possible the discrimination of a great variety of color and form.

Life now seems to move in a vastly richer and more varied world than that assigned to it in the last chapter : light and heat are important aspects of it, while smells, sounds and colors are distinguished. In fact sentient life moves in a realm that is characterized by secondary as well as primary qualities. Psychologists experiment with sensory discrimination and deal directly with sounds, tastes and odors as well as with lights of different colors, intensity and direction. Now if sensation is understood to be one form or kind of consciousness, it may be said that we have gone beyond the domain of physical life and entered that of psychical. As these are commonly considered to be mutually exclusive and quite distinct, and even of opposite nature, it is rather strange that we have passed so easily from the one to the other. But I think that there is much to be said against regarding sensations as elements of mind, as I hope will be clearer after our discussion of mind and consciousness in the next chapter. For the present I simply want to point out that sensation may be regarded as a physical or physiological fact or event, a function of the organism and specific aspects of its environment, and expressible in terms of interaction between them. Sensation is thus dependent on both the organism and its environment and varies with either of them. Thus a rose may appear red to most people, but not at twilight or to a color-blind person. Similarly there are physical or physiological explanations for the socalled illusions of the senses that have caused so much trouble when treated as epistemological problems: thus the straight stick partly immersed in water appears bent because of the difference of refraction of air and water; the tepid water feels hot to one hand and cold to

8 Cf. Washburn: Loc. cit., Chapter V. 
the other because it is warmer than the one and cooler than the other; and parallel lines seem to converge and square towers at a distance look round because of the laws of perspective and optics and affect the sensitive plate of a camera in the same way that they do our eyes.

Of course I do not mean that we may not be conscious of sensations but only that they are then objects of consciousness and not its elements. Their existence is thus not dependent upon consciousness but upon the functioning of an organism. The same seems to be true of pain and pleasure and of feeling and emotion as well, as these appear to depend directly upon the condition of the organism and to be intimately connected with its behavior. Emotional life may thus be regarded as one form of sentient life. The chief characteristics of the latter would then be sensation, emotion and behavior. We have already indicated something of the close relation between these and also the wide range and variety of animal behavior; probably sensation and feeling differ quite as much, the former depending largely upon the degree of the differentiation of sense organs, the latter probably upon the complexity and organization of the bodily processes, especially the nervous system. But this is not to be understood as implying that the lower animals including the unicellular are without sensation and feeling, for Jennings has found that they respond to stimuli in different ways and possess discriminating sensibility. He also notes that they appear to desire and hunt food and react to injurious agents as if in pain. ${ }^{9}$

We have now to examine these characteristics of sentient life to see what light they throw on the nature of life as it appears in this realm. Behavior here appears to be an interaction of organism and environment in a fashion somewhat parallel to metabolism in vegetative life. The difference between them is most evident in the higher forms of animal life where different systems of organs have been developed for each, while their close relation is more evident in the lower forms where there is less differentiation of function. But everywhere the behavior and metabolism of the organism are closely interrelated and sentient life is continuous with nutritive life.

What an organism does in any situation is dependent upon its condition and the nature of the stimuli affecting it: that is, behavior is a function of both organism and environment and is thus dependent upon both internal and external factors. The fact to be noted first is that activity and movement appear to be characteristic of organic life; external stimuli thus influence rather than cause behavior, and the energy required for this activity is derived from the metabolic processes within the organism and is not furnished by the stimulus,

9 Loc. cit., pp. 329-332. 
the action of which rather resembles the pulling of a trigger than a mechanical push. The action of an organism also depends upon its structure and the character of what Jennings calls its "action system": thus the lower organisms possess only a very limited number of possible responses, while greater differentiation of organs together with their integration by the nervous system places a great variety of action at the disposal of the higher animals. The behavior of an organism is thus dependent in a general sense upon its past growth and development as supplying the mechanism and energy for action. Even so a given stimulus does not always set off the same response, as the specific state of the organism at the moment is important as well as its general character: for example hungry and well-fed animals react differently to food. ${ }^{10}$ Even Loeb's attempted reduction of instincts to tropisms shows that these vary with physiological conditions so that "in ants. the winged males and females become intensely positively heliotropic at the time of mating . . . after copulation the female loses its wings and also its positive heliotropism. It becomes now intensely stereotropic. ${ }^{11}$ Similarly a caterpillar that is forced by its heliotropism to climb up a plant stalk to the leaves, after feeding upon these "loses its positive heliotropism almost completely and entirely." 12 Now the condition of an organism is, as we saw in the last chapter, closely connected with its temporal structure. This is most commonly expressed in a recognition of the effect of the past upon it, but behavior seems also to possess a future reference. Thus an adequate description of the behavior of organisms requires reference to their temporal structure.

This of course becomes more important and evident with the development of higher forms of behavior and with the increasing prominence of learning. Indeed in the learning processes of the higher animals the temporal structure of sentient life becomes very obvious. Much experimental work has been done in this field, especially with the ability of animals to learn to run mazes and to manipulate simple locks and puzzle-boxes. Learning here progresses by the method commonly called that of trial and error, useless or harmful movements being gradually eliminated and the desired result more rapidly attained.13 Here a teleological as well as a temporal aspect seems evident, as acts

${ }^{10}$ Cf. S. J. Holmes: The Evolution of Animal Intelligence, New York, Holt, 1911, pp. $150 \mathrm{ff}$.

11 Forced Movements, Tropisms and Animal Conduct, Philadelphia and London, Lippincott, 1918, p. 158.

12 Ibid., p. 162.

13 Cf. Washburn: Loc. cit., pp. 257-285. 
are usually performed in order to obtain food or to avoid punishment. The same would seem to be true of a great part of animal behavior, which appears to be in general adaptive in that it keeps or brings the organism into conditions that are favorable to the continuance of its life processes. The simplest forms of behavior seem to be food getting and avoidance of injurious stimuli. With the higher organisms, especially man, other ends are sought and attained, but self-preservation, together with the sometimes incompatible aim of preserving the species, certainly remains fundamental in the types of life that we have so far considered. Thus Singer would define life as purposive behavior and give self-preservation as the defining purpose. ${ }^{14}$ But definitely purposed or voluntary action would seem to require consciousness in the sense discussed in the next chapter, and thus to go beyond instinctive and emotional reactions. It thus seems that the teleology characteristic of sentient life is still unconscious and of the same general type as that which we found to be one of the features of biological life.

Indeed vegetative and sentient life appear to be continuous and in fact may be regarded as but two aspects of biological or physical life. This is particularly evident with the lower organisms, for their behavior and metabolic processes are so closely connected that it would seem unnatural to assign them to different worlds. But with the higher plants and animals the case seems different, for we recognize a high degree of organization in the former without any corresponding development in behavior, while with the latter behavior and sensation may be developed to such an extent that their connection with other aspects of physical life is obscured and they may come to be conceived as phases of conscious life. The distinction between the two seems to be expressible in terms of the domains or realms in which they move, for it seems possible to conceive of vegetative life existing in a purely physical and chemical environment and we imagine that plants may have existed on our earth before the appearance of animals. Similarly the metabolic processes of biological life seem to be largely expressible in physical and chemical terms if once the organism with its temporal structure is given. In other words nutritive life moves in a mechanical and chemical domain, while with sentient life we seem to have moved into a wider and more varied realm. Light and temperature, taste and smell, sound and color become important factors; $m, l$, and $t$ are no longer sufficient for its description and even a recognition of the differences of chemical elements is inadequate. Sentient life thus moves in a world of great wealth and variety of secondary and even tertiary as well as primary qualities.

14 "The Pulse of Life," Journal of Philosophy, Vol. XI, p. 650. 
But however different the realms of vegetative and sentient life may appear, the continuity of these two forms of life is quite as evident. The biological organism whose development and organization we examined in the last chapter, appeared in the present one as an individual center of activity. In both cases our analysis of life has shown the importance of its temporal structure. In the case of vegetative life this was most evident in the growth and development of the organism, but appeared to be essential as well for an understanding of its specific form and chemical composition. While in that of sentient life it was specially obvious in connection with learning, which possesses a future reference as well as depending upon past experience; but all behavior and sensibility, so far as their appearance in concrete cases is concerned, appeared to be dependent upon the temporal structure or life history of the individual organism of which they are functions.

The teleological aspect of life that we noted in connection with organic growth was made more prominent by our examination of behavior. Here it is evidently to be conceived in terms of use, as the helping or hindering of definite tendencies. The organism appears as a specific center of interest to which its environment contributes in varying degrees. We have seen that the lower organisms react to a stimulus according to its influence upon their life processes, that they seem to discriminate only between food and injurious stimuli and thus appear to be sensible of pleasure and pain as connoting "normal, unhindered functioning" and the interruption or hindering of such functioning. Indeed this seems to be the nature of sensuous pleasure and the "specific quale of this type of value lies in its helping to fulfil a certain fundamental tendency resident in the organism," namely "to perpetuate its own normal unhindered functioning."15 Thus teleology in so far as it appears in connection with sentient life seems to be very closely connected with its temporal structure; for life processes are specific and directed tendencies, such for example as those evident in the growth and development of their specific forms, but characteristic also of their metabolism in general; now anything that aids these tendencies is of use to the organism, while anything that hinders them is injurious to it. Other things and processes thus have positive or negative value for it in so far as they help or hinder it in its life processes. If "the value of an object consists in its helping to complete or fulfil some tendency already present," 16 the close connection

15 W. H. Sheldon: "An Empirical Definition of Value," Journal of Philosophy, Vol. XI, p. 115 .

16 Ibid., p. I2I. 
of teleology and temporal structure is evident, for in a world that was permanent or whose changes were chaotic or undirected there would be no specific tendencies to be helped or hindered and so values in the sense just defined would be impossible. Indeed it is only in a world that has temporal structure that progressive change and development can occur and action be directed toward ends. The temporal structure here indicated evidently implies both duration and direction and is not to be identified with the mathematical time of physics. 


\section{CHAPTER IV}

\section{CONSCIOUS LIFE AND MIND}

Life as pictured in the last chapter, moving in a world of colors and sounds as well as possessing mechanical and chemical structure, doubtless appears to resemble very closely what is often termed conscious life. But we were there dealing with physical and physiological facts and there seemed to be no need of introducing any mysterious subjective factor. Indeed sentient life seemed quite clearly to be a special aspect of biological life: thus we could speak of vegetative and sentient life as two forms of bodily or physical life in the broad sense of the term; and behavior and sensation seemed to be physiological processes quite as much as did metabolism.

We are now to consider conscious or mental life, and may begin by indicating how it differs from sentient life and why we are treating it in a separate chapter. The common tendency to treat sensation and emotion as forms of consciousness parallel with thought or cognition perhaps makes our division seem strange and artificial, and anyone who prefers may regard the preceding chapter as dealing with one aspect of conscious or psychological life rather than, or as well as, with biological life. Of course most psychologists would do so and that was my original intention, but the division between the facts with which psychologists and biologists deal did not seem to be at all clear and indeed the whole range of psychology appeared so confused that it seemed best to divide our discussion of life as the material with which we were dealing seemed to indicate rather than try to follow the lines of demarcation between the various sciences that treat it.

The fact that psychologists may question the existence of consciousness, often preferring to define their science in other terms, and seldom attempt to tell what they mean by consciousness aside from giving varied and confused lists of what it is supposed to comprise, further made it doubtful whether we could get much help from them as to the exact nature of conscious life. If we turn then to recent philosophical discussions of the nature of consciousness, we find that epistemological problems and difficulties have caused considerable, not to say bewildering confusion in this field. But examination shows that a part at least of the trouble is the result of confusing the facts of sensation and emotion with their possible cognitive relations and of treating sensation per se as cognitive. Thus consciousness is defined in terms of the 
interaction of organism and environment, which obviously gives a definition of sensibility and behavior, but fails to distinguish these as unconscious from their conscious phases. This has seemed less absurd than might have been expected, since subconscious and unconscious psychical processes are generally admitted and though psychical and conscious are commonly taken as synonyms, to call the former unconscious does not appear to most people a contradiction in terms. The whole situation seems to be the result of a philosophical conception that set consciousness over against the physical world, made the gulf between them impassable for either and had to manufacture an unconscious consciousness, or to cover the contradiction an unconscious psychical realm, to contain what might be conscious but was not so at any given time. Of course in some systems this latter function was neatly performed by God or the Absolute.

However our present concern is not with philosophical systems, but with the facts of conscious life. I propose therefore to identify consciousness with awareness or cognition rather than with the vague realm of the psychical. But anyone may include what was said in the preceding chapter as well as much that will be discussed in the following chapters as aspects of conscious life if he so prefers. My present interest is not to defend any particular concept of consciousness nor in fact the definitions of any of the realms in which life is found, but rather to get before us as clear a picture of life as possible in each case.

What then is the fundamental characteristic of conscious or mental life? It is in a word knowledge, cognition or awareness. Sensations and emotions enter consciousness when one is aware of them, but when they remain below the level of consciousness they are simply physical and physiological processes and as such were treated in the last chapter. How they look outside of consciousness we of course can not know, for it is impossible to know an object without being aware of it. But the so-called "ego-centric predicament" appears to be no different here than. elsewhere, for it is always impossible to know objects outside of knowledge. We have then to examine more carefully the nature of knowledge if we are to get a definite picture of mental life. An identification of knowledge with awareness emphasizes immediately its relational aspect and also the wide range of its objects, for one may be aware of chairs and tables, solar systems and ethical ideals, in fact the whole realm of objects of possible knowledge, universals as well as particulars, past and future as well as present. It is thus evident that the domain in which conscious life moves is vastly greater than those of vegetative and sentient life; for one thing its effective environ- 
ment is greatly extended in both time and space, but that is by no means the only difference between unconscious and conscious life for things have a meaning for the latter that they did not possess for the former.

In fact meaning seems to be the essential feature of consciousness. If this is the case, the sensations and images or ideas that are commonly regarded as its elements rather appear to be its objects, the bearers or carriers of knowledge than knowledge itself. They thus figure as symbols or signs whose function it is to suggest something beyond themselves and thus require interpretation. Life thus comes to move in a realm where things have meanings and implications as well as mechanical and chemical structure. The self-transcendence of objects here suggested shows that they belong to a logical structure that may be termed "mental" or "transcendental,"1 and regarded as neither temporal nor spatial, though these same objects may also belong to temporal and spatial structures as well. Indeed in many, if not most cases, this self-transcendence of the objects of consciousness appears to possess a very definitely spatial and temporal aspect, since consciousness is both retrospective and prospective and its stimuli may recede in both space and time as consciousness develops. ${ }^{2}$ That is, for conscious life the meaning and implications of its objects depend upon the fact that memory and imagination are essential and fundamental as well as awareness, and indeed are implied by it.

Like other forms of cognition, memory always seems to possess a sensational (images here being included as well as sensations proper) basis, which appears to be important as the carrier of meaning rather than as the memory itself; and the images may vary from a vivid picturing of the past through all degrees of sketchiness to merely verbal images, and if these all refer to the same fact or event they would be recognized as so far the same memory however different were the images on which they were based. Here again meaning rather than sensuous content seems to be the essential characteristic of consciousness or mind. But in this connection the meaning must be recognized as referring to the past, which shows the importance of temporal structure for conscious life. Though memory is usually referred to as reproductive imagination, it is evidently no mere repetition and frequently possesses a productive aspect as well, as is particularly apparent in learning. In a similar way, so-called creative or productive imagination possesses a past as well as a future reference and the same is true of anticipation. Thus if the term imagination is

1 Cf. Woodbridge: "Structure," Journal of Philosophy, Vol. XIV, p. 683.

2 Cf. W. P. Montague: "A Realistic Theory of Truth and Error," The Nere Realism, New York, Macmillan, 1912, pp. 278-285. 
used to cover all these aspects, it clearly indicates the importance of temporal structure for conscious life; especially when we realize that in experience all awareness, whether perceptual or conceptual, is really a special case of imagination where we have no particular interest in its temporal reference whether past or future. For the meanings that things have for us are so universally connected with our past experience and our interests and purposes that we often give the fact but scanty attention.

Our discussion of consciousness thus brings us again to a consideration of purpose, the importance of which has already been suggested in connection with behavior. Perhaps the most commonly emphasized characteristic of purpose is its relation to temporal structure, for purpose would seem to be meaningless in a non-temporal world. The temporal structure here required would evidently be one in which direction was important, or in other words it is "duration" and not merely mathematical time which is in question here. The same is perhaps even more evident in connection with memory, since the cumulative aspect of duration is here especially prominent. Unfortunately the future seems to have been always more difficult to deal with than the past, because it somehow seems easier to conceive that the past is preserved in the present than that the future can be operative in the present. Now it seems to me that at least a part of the difficulty has been due to the fact that practical and theoretical considerations have been allowed to become too thoroughly intertwined, with the resuit that we have nothing like as clear a conception of temporal as of spatial structure. This appears to be one reason why we are constantly trying to compress all temporal structure into the present and treat memory as though it made the past present, and anticipation and purpose as though they could make the future in some inconceivable way present. But that neither memory nor anticipation in reality aim at such an accomplishment would seem to be evident enough from the fact that their intention is to refer to past or future without being them. As a past event is not made present by being remembered, so a future event is not made present by being imagined; for in either case it is the idea or image that is present, while its meaning is its past or future reference. In fact meaning always seems to require a transcendence of present date, as is perhaps even more evident when it is expressed in terms of implication, and though this can evidently be developed in logic without reference to temporal structure, its appearance in conscious life seems to be dependent upon the temporal structure characteristic of life, in much the same way that the mechanical 
and chemical structure of biological life can be understood only in connection with its temporal structure.

However, purpose is characterized not only by its temporal aspect, but is evidently also closely connected with what we have called teleology : in fact purpose is often identified with teleology or taken as its defining characteristic. But in the sense in which we have been using the term teleology, purpose appears to be merely a special case of teleology that becomes possible with consciousness. Indeed consciousness gives new efficacy to both the temporal and teleological factors of life. On the physical plane they appeared rather as characteristics of life than as factors in its processes. ${ }^{3}$ The growth and development of biological organisms quite clearly conform to temporal structure, and in fact we have seen that no aspects of living beings could be adequately understood aside from their temporal structure and teleological organization, but neither of these appeared as effective factors in bringing about their own embodiments : efficiency in this realm apparently being confined to mechanical and chemical factors. In other words, temporal structure and teleology appeared as characteristics of life rather than of the physical realm in which it was finding embodiment. With sentient life that domain seemed to be extended considerably, as it included what are commonly called secondary and tertiary qualities as well as the primary ones; there seemed also to be recognition or rather feeling of use in the discrimination of food and the avoidance of injurious stimuli. But with conscious life both temporal structure and teleology gain immensely in importance; the past is definitely remembered and used and the future is consciously planned for. The varied uses of things are recognized, advantage and disadvantage are anticipated and means taken to gain the one and avoid the other. ${ }^{4}$ Consciousness thus seems to open the door to a most varied world and in fact appears to be so essential to many other forms of life, some of which will be considered later, that the term conscious life might be used to cover all these as well as sentient life. But in the narrower sense of the term which we have for the present adopted in the interest of clarity, mental life is to be conceived as moving in the realm of logical structure which is definable in terms of implication and meaning. Its elements may be anything so long as they conform to its structure; they thus include physical objects, sensations, ideas, universals, values, ideals-a varied host, indeed anything that may be known. Conscious life in the broad sense of that term is of course concerned with many of their aspects, but mental life in so far as it is contrasted with other

${ }^{3}$ Cf. F. J. E. Woodbridge: "Natural Teleology," Essays in Modern Theology and Related Subjects, New York, Scribner's. 1911, p. 323.

4 Ibid., p. 323. 
aspects of personal life, is to be conceived as moving in the realm of logical structure, rather than as including all the forms of life that would be impossible without consciousness.

The preceding discussion has shown, I think, that the characteristic feature of consciousness or mind is meaning and that sense qualities are rather a basis of knowledge than knowledge itself, that is they are the objects of knowledge or its signs or symbols and the same is apparently true of pleasure and pain. Though it has been customary to regard these latter as well as knowledge as aspects of consciousness, we have tried to clarify the discussion of psychological or conscious life by distinguishing between sentient and mental life. The characteristic marks of the former would be sensibility in its two aspects of sensation and feeling, both of which are to be understood in terms of the relation or interaction of organism and environment and thus as a function of either according to the way in which one wishes to express it. But in so far as they are physical facts only, they would not seem to be rightly called conscious, which they become only as they assume meaning or are related in special ways either among themselves or with other objects. But though in general we readily distinguish things from their meanings, in the case of sensations and feelings the two seem to have been pretty thoroughly confused, so that in this case the objects of consciousness have been assimilated to consciousness, and some of the neo-realists having noted this fact have carried it farther and identified consciousness with a class of objects ${ }^{5}$ of any sort. Now it seems to me that objects are no more consciousness than they are time or space and in fact their relation to logical structure is similar to their relation to mechanical and chemical structures.

Meaning and logical structure thus might be independent of organisms, and mental life go on without any connection with physical life if it could build up a progressive organization of elements derived from a logical environment: that is, if there were objects that possessed only logical structure, an independent mental life might be possible, but I should think that it would be useless and at any rate speculations conr cerning it are idle as conscious life as we know it is found only in connection with physical life. On the other hand there may be sentient life that can not rightly be called conscious, and it would seem to be this of which we find clear evidence in the case of animals. Singer's discussion of sensibility ${ }^{6}$ and Jennings's descriptions of the behavior of

5 E.g. E. B. Holt: The Concept of Consciousness, New York, Macmillan, 1914, p. 182 .

- In the Journal of Philosophy, Vol. XIV, pp. 337-350. 
the lower organisms seem to show clearly that we are there concerned with sentient rather than with mental life. The same is apparently the case with many of our reflex and habitual reactions which depend directly upon the proper functioning of our sense organs, but still are generally recognized as unconscious. If this is the case, sentiency or sensibility may well be identified with a type of behavior and is properly a subject for biological investigation; in fact much that is now studied under the title of psychology would seem to belong under this head. Sensibility is then one of the characteristics of physical life, at least as it appears in many animal forms, varying in degree with the development of the organisms and the increasing differentiation of their sense organs and integrative action of their nervous systems. Sensation so ronceived as an object of knowledge and not as a type of consciousness would be a purely physical or rather physiological process, and the same would be true of pleasure and pain and indeed of all the affective aspects of "consciousness." But these various vital processes also often figure in logical structures, they are related by way of meaning and implication or "act as a part of a system of symbolization" 7 and thus enter consciousness.

Since our conscious life is based directly upon sensibility in its various forms, the connection between sensation and cognition has been taken or rather mistaken for one of degree rather than of kind, so that sensation is conceived as an elementary form of knowledge, or inference as an unsatisfactory substitute for intuition. But if our analysis has been correct, sensation and knowledge are radically different however closely they may be connected in practical life. As meaning has been shown to be the essential factor of our cognitive experience, it appears as the distinguishing feature of mental life. So conceived mental life would not include our entire inner or spiritual life, but rather appears as one aspect of it perhaps roughly parallel with our moral or our esthetic life. It may thus be regarded as one phase of our personal life stressing certain aspects of it, namely the interpretation of meaning and logical relations. That is, mental life is lived in the realm of implications and meanings, just as biological life occurs in the domains of physics and chemistry; or mental life may be said to operate within logical structure as biological life does within mechanical and chemical structures. But in neither case is life to be identified with its medium or environment, though this may furnish the distinguishing mark of the different kinds or grades of life.

7 A. Meyer: "Misconceptions at the Bottom of 'Hopelessness of all Psychology,'" Psychological Bulletin, Vol. IV, p. 178. 
The logical domain, which may be called "mind in a metaphysical sense" as distinct from mental life or from individual minds, appears to be as timeless as are the spatial and mechanical domains, but spaceless as well, for logical structures "have that kind of aloofness from time and space which we indicate by the ordinary word 'mental' and the extraordinary word 'transcendental." " 8 Objects within this domain are related by implication and suggestion. Thus sensations and feelings appear within it as signs or symbols that may be variously interpreted. They, like all other objects and events, appear to possess a great multiplicity of meanings or implications, and mental life seems to consist in the selection and organization of certain of these into individual wholes. The possibility of such an organization appears to be dependent upon the temporal structure characteristic of life. In other words, life on the mental as well as on the biological plane appears to be continuous with its environment from which it selects the elements which form the basis for its characteristic organization, which in turn can be expressed only in terms of its temporal structure. The importance of this in connection with such conscious processes as memory and anticipation is evident and our analysis has shown that the same is true of all cognitive processes, for as Dr. Carr says "to be conscious or aware of an object is not to contemplate it but to recognize it. Recognition implies precognition, . . . presupposes memory and also constructive imagination." 9 That is, consciousness as it occurs in concrete forms is very definitely a temporal affair, however timeless mental or logical structure may be in itself.

This clearly indicates that the organization characteristic of mental life is not to be unthinkingly identified with logical structure. Perhaps the difference between them can be most pertinently expressed by pointing out that mental life is always connected with individuals which may be called mental organisms after the analogy of biological organisms, though they are probably more commonly spoken of as individual minds or as selves. But the latter terms seem to imply greater richness and variety of content and organization than seem to belong to mental life in the restricted sense in which we are now using the term, for they are commonly understood to include the entire inner life, moral and religious as well as mental. Individuality thus appears to be one of the fundamental characteristics of mental life. This was suggested on the biological plane by the importance of specific form and is commonly considered in psychology under the heading of personal identity. The fact that this is most evident in recognition and memory, and in

8 Woodbridge: "Structure," Journal of Philosophy, Vol. XIV, p. 683.

9 "The Interaction of Mind and Body," Proceedings of the Aristotelian Society, Vo!. XVIII, p. Io. 
anticipation and hope shows very clearly that it is closely connected with temporal structure, which is evidently required for the continuity and development of the self and indeed for its very organization. For the characteristics of an individual mind depend upon its past experiences and its aims and interests, both of which determine the selection that it makes from the many meanings and implications presented to it.

In conclusion, it may be interesting to compare mental and physical life as their characteristic features have been brought out in this and the preceding chapters. In both cases life presented a typical organization of elements that were derived from its environment or medium. The fact that these possess very different structures in the two cases, would account for the difference between mental and physical life. The adjectives thus appear to characterize the domains in which life is found rather than the nature of life itself, and thus describe the elements which furnish the basis of its organization. This organization, characteristic of life, seems to be most naturally expressed in terms of differentiation and integration, or of selection and assimilation, and can be understood only in connection with its temporal structure. It also seems to require individualization. Biological organisms are so obviously individual centers of activity that we failed to note this as one of the essential characteristics of life on the physical plane, but the attempt to distinguish mental life from mind in general showed how important is this aspect of life. Driesch and Singer ${ }^{10}$ have suggested it in their discussions of the teleological aspect of life and indeed it may be the best way of calling attention to the non-mechanical aspect of life. Thus life so far as its elements or material is concerned appears to be continuous with its environment or the plane on which it is moving, but the principle of its organization seems to be at right angles to this, if we may use a spitial figure in such a connection, and to involve the selection and assimilation of those elements which can be built up into the individual form of life in any given case. This principle of organization is sometimes described as teleological, though a term with less confused connotations would be desirable. Still it is difficult to find terms to express the exact meaning which seems to require some combination of individuality and teleology; and we shall continue our examination of it in the next chapter.

10 For example Driesch's constant emphasis upon the importance of factual wholeness of the individual organism and definition of teleology by reference thereto. (Cf. Problem of Individuality, p. 3.) While Singer's discussion of purpose and freedom and especially his selection of self-preservation as the defining purpose of life show a similar tendency to connect teleology and individuality. ("The Pulse of Life," Journal of Philosophy, XI, 645-655.) 


\section{CHAPTER V}

\section{VALUES AND THE MORAL LIFE}

We saw in the last chapter that consciousness made possible a recognition of the uses of things and so the conscious utilization of them. Life thus comes to move in a realm of recognized values, and the selection and organization of these goods may be regarded as characteristic of the moral life-in Woodbridge's words, "with consciousness, the world's teleology is a moral teleology." 1 We may therefore pause for a survey and consideration of the aspects of teleology that have already come to our attention before proceeding to a direct examination of the moral life. Here we shall need to keep in mind constantly that our problem is merely one of definition with no attempt at explanation, for most discussions of teleology have been greatly confused by attempts to explain it. But our present aim is to analyze and define teleology in such a way as to make its significance as clear as possible, especially in reference to its relation to life.

The discussion of life on the biological plane has already shown how inevitably we regard life processes as teleological and the examination of behavior further emphasized the purposive aspect of life, while with consciousness it became even more evident in conscious purpose and planning. The facts thus indicated are numerous and have been variously expressed by such words as fitness and adaptation, selection and use, purpose and design. Thus organic growth and development may be described as teleological in the sense that through the selection and assimilation of material derived from its environment the organism preserves its individuality. As has already been suggested, this aspect of life seems so important to Singer that he defines life as purposive behavior and gives self-preservation as the dominant purpose. ${ }^{2}$ Indeed an examination of the behavior of organisms shows that life processes are most naturally described in teleological terms. This does not mean that they are not at the same time mechanistic in the sense of conforming to the mechanical and chemical structure of their environment. For the same thing may be both mechanical and teleological without the distinction between the two categories being in the least blurred. For example, a machine is the common symbol of perfect 1 "Natural Teleology," Essays in Modern Theology and Related Subjects, p. 324.

2 "The Pulse of Life," Journal of Philosophy, Vol. XI, pp. 647-650. 
mechanism and its action conceived as purely mechanical, but it is at the same time one of the most obvious instances of design and purpose. Thus there appears to be no incompatibility between mechanism and teleology as descriptive terms and the common opposition between them appears to result from an attempt to determine their relative merits as explanations on the same level. In the battle over these, evident facts have been lost sight of, facts and theories have been confused, and interest in the latter has obscured the former until unprejudiced description seems to have become almost impossible. We have now to attempt to find our way through this tangle with the hope of making as clear as possible the nature of teleology and its connection with life.

Attention has already been called to the teleological aspect of the growth and development of organisms. The acorn develops into the oak, as has so often been remarked, and the germs of animals into adults of the same species, and individuals maintain themselves amid considerable changes in their environment and within limits adapt themselves thereto. Their metabolism, which is so obviously chemical, has a teleological aspect as well, since it proceeds by selection as well as assimilation and is most naturally described as the maintenance of the individuality of the whole through constantly changing matter or the attainment of a definite end through a variety of means. In fact teleology and the organization that has appeared to be characteristic of life seem to be very closely related, as both emphasize the importance of individuality and wholeness in contrast with undifferentiated multiplicity. We had thus been led to define life in terms of its selection and organization of elements, not forgetting that these processes are distinctly temporal and non-static. In fact it is one of the interesting features of teleology that it seems to imply temporal structure as well as use or value. Value here must be understood in a very general sense as covering use, adaptation, fitness as well as planned or purposed ends, and I would use it to indicate the aspect of teleology other than its temporal structure.

The teleological aspect of life on the biological plane is probably even more evident in connection with the behavior of organisms than in their growth and metabolism. Mechanistic attempts to give an account of the behavior of animals in terms of merely mechanical and chemical reactions show how inadequate such terms are to furnish complete descriptions of the facts under observation. The behavior of the bee gathering honey or the man going to buy a new house may perhaps be best "explained" in terms of tropisms and chemical stimuli, etc., but these evidently furnish but a poor and ridiculously scanty description of the activities which are certainly more naturally and adequately 
described in terms of ends or purposes. Indeed so much of the action of living organisms is evidently adaptive or purposive that it can not be easily described in wholly non-teleological terms. But this is not to be understood as necessarily implying the presence of consciousness in any particular case, for though purposive behavior is sometimes given as a criterion of consciousness, this like the others commonly given seems to show the presence of sensibility rather than of mind and so does not prove the presence of consciousness. We further recognize many cases of adaptation and fitness without reference to consciousness, so we should be careful not to identify teleology with conscious purpose; and in fact Henderson's discussions of "the Fitness of the Environment" and "the Order of Nature" seem to show that it is not even limited to the biological realm but is found in inorganic nature as well. If this is the case, it would appear to be a category of very wide range, applying to the properties of the chemical elements, the growth of plants, the behavior of animals and a great variety of human actions.

Though teleology is thus not to be limited to conscious processes and activities, it is more commonly recognized in such connections, and attempts made to explain it rather than to explain it away usually end by resorting to "a psychic factor."' But this is not our purpose in connecting teleology and consciousness, as we have forsworn all attempts at explanation. We however need to keep in mind the various forms in which teleology appears, if our discussion of it is to be comprehensive. We may thus note that while in the realms of unconscious nature we commonly speak of adaptation and fitness, of selection and use, on the conscious planes we more naturally employ such terms as purpose and design, value and goods. If the analysis of consciousness in the last chapter is correct, the difference between conscious and unconscious teleology is to be understood in terms of implication and meaning. But neither biology nor psychology seem to take adequate account of the importance of teleology and value for life. This is commonly recognized by classing both as sciences and contrasting science and value, the latter being regarded as the subject matter for ethics, esthetics, etc. which are then denied the title of science in the strict sense of the word, though they are sometimes called normative sciences. I am not interested to discuss these distinctions at present, but we may note that teleology and value seem to play a more prominent part in moral and religious life than in physical and mental life. In fact the most significant aspects of our inner or spiritual life have to do directly with values and ideals. The same may be said of certain

3 Cf. L. T. Hobhouse: Development and Purpose, London, Macmillan, r9r3, Pt. II, ch. 4, especially p. 328 . 
aspects of our social life-national and church life emphasizing the ideal aspect, while economic and business life rather stress the practical values.

The facts of use and adaptation seem to be quite as natural as those of form and activity; square pegs do not fit round holes and some processes help while others hinder one another. Thus things are related as means and ends as naturally as they are as cause and effect. The fact that many processes may be described in either causal or teleological terms, by no means implies that the two are the same or that one is dependent upon the other. We have already had occasion to note that a thing may belong to many orders or conform to many structures without any confusion resulting, so long as distinctions are kept clear and the terms appropriate to one are not applied to another. The moral here is that means and ends are not to be confused with causes and effects, as they are descriptive of different types of order and only confusion results from treating ends as a new type of cause. It is a failure to recognize this that is at the bottom of at least a part of the confusion and misunderstanding in the controversy between mechanism and vitalism and also of much of the ambiguity in the statements of the latter. For discussions of teleology have generally led to a reduction of it to some sort of mechanism or the ascription of it to consciousness or mind often of a sub- or super-normal form: that is it has been conceived as the result of necessity or design.

Now without any attempt at explanation, let us try to get before us as clearly as possible the exact meaning and implications of teleology. Though we have seen that it is variously expressed by such terms as adaptation, fitness, purpose and design, it is perhaps most clearly and simply described in terms of means and ends. Thus the teleological realm is that in which things are related as means and ends. Such a statement suggests the complexity of the relation as well as its asymmetry. The distinction of means and ends is evident and is apparently essential to any teleological order or value situation. Thus means serve ends or are valuable by reference to them, or may be regarded as fitted or adapted to bring them about. Here the means are often conceived as valuable or useful for the end or simply as good by reference to it, and thus the value that we naturally regard as characteristic of teleology seems to be ascribed entirely to one of the terms of the relation and the means alone appear to be valuable while the end may be described as invaluable, as either beyond or outside the range of valuation. But this seems to be a rather strange, not to say contradictory, state of affairs, since it is the ends that usually seem so important for any value situation that they are commonly considered 
to be goods or values. Would it be better then to attribute value to both means and ends? If we do, we shall have to distinguish between intrinsic and extrinsic, between immediate and instrumental values, for the distinction between means and ends must be maintained if there is to be any teleology and value. Under the circumstances may we not follow the lead suggested by our analysis of consciousness and conceive value like mind as a relation rather than as a term, attribute or quality? Sheldon would give an affirmative answer to this question for he finds "the same logical structure" in all cases of value, namely "given any tendency, in dead nature, in living organisms, in conscious minds, which presses toward a certain end: any other tendency that furthers this is for it a good, and any that resists it is for it bad."4 Thus " 'good' is the relation between the fulfilment (or furthering) and the tendency; a relation uniquely determined, and sufficiently determined, by the two." ‘

Such a definition of value in terms of tendency seems to require directed change and so would be impossible in either a static or a chaotically changing world. In fact its temporal aspect can be emphasized until teleology is identified with any future reference or even with the future portion of temporal structure. But however closely teleology and temporal structure are related, they certainly are not identical. The confusion of them is apparently the result of using both as explanatory categories in the sense of final causes that are effective, probably through the medium of consciousness, in bringing about action in the present. Now temporal structure as we have been using it could never be employed in a causal sense, for it is essentially an inert principle to which existences conform. We have also urged that the distinctions of past, present and future are the result of our practical interests and that an adequate comprehension of the nature of temporal structure would require a treatment of it that would transcend these distinctions in the same way that geometry has that of near and far. This is not to be understood as a denial of the close connection of teleology and time in all concrete cases. Again the relation seems to be very similar to that noted in the case of mind or consciousness, for there logical structure or mind in a metaphysical or universal sense appeared to be quite unconnected with time, or timeless and eternal, while particular meanings as they occur in individual minds are very. evidently connected with the temporal structure that these possess. Similarly the important aspect of teleology as descriptive of a new

4"An Empirical Definition of Value," Journal of Philosophy, Vol. XI. p. 121 .

ฐ Ibid., p. 122. 
order of being is value or use, while its temporal aspect would seem to be ascribable to its concretion in particular instances. This is perhaps most obvious in connection with conscious purpose whose anticipatory aspect is so evident, for consciousness seems to make possible a more extended temporal range.

It is in this world of values that the moral life moves: it appears to be a realm of varying extent, which may be nearly as wide as that of consciousness while in a sense it may include certain aspects of the unconscious as well. For though morality would be impossible without consciousness, conscious and moral life are not commonly identified, morality being more closely connected with the teleological order of things than with their logical structure. Thus the values with which the moral life is concerned, are by no means confined to the mental or intellectual values but include as well "goods of the physical sort, such as health, bodily comfort, sensuous pleasure," "the goods of artistic appreciation," the goods of human character and of social life, such as friendship, courtesy, honesty, peace, coöperation, etc. ${ }^{6}$ In fact it would seem to be because of the plurality of values of varied types that the problem of ethics so often appears to be the determination of a single summum bonum. For evidently it is impossible for a single life to include all values because of their multiplicity as well as their incompatibility, as "Professor James writes piquantly: No man can be 'a great athlete, and make a million a year, be a wit, bon-vivant, and a lady-killer, as well as a philosopher; a philanthropist, statesman, warrior, and African explorer, as well as a tone-poet and saint';" and "to each of us, of all the possible careers-not remotely or hypothetically possible, but reasonably available under realizable conditions-one alone becomes actual."' Indeed moral life like physical life requires definite organization and an attempt to include all values would be as disastrous here as it would be on the physical plane for an organism to try to absorb everything that came its way or to develop into all forms of organic life at once. Organization requires selection and sacrifice, the psychical as well as the animal organism must be something definite to be at all, and like the germ or embryo maintains itself by assimilating what favors its task. 8

In other words the moral life appears to be a particular organization

6 S. P. Lamprecht: "The Need for a Pluralistic Emphasis in Ethics," Journal of Philosophy, Vol. XVII, pp. 562-3.

7 J. Jastrow: The Qualities of Men, Boston and New York, Houghton Mifflin Co., 1910, p. 65.

8 Cf. E. Gilson: "Essai sur la vie intérieure," Revue Philosophique, Vol. LXXXIX, p. 33 . 
of values. Now the method of this organization is variously described in terms of discrimination and integration, of selection and assimilation, of rationalization, socialization or idealization. However in every case they seem to imply a process directed toward a more or less definitely conceived end and conforming to the temporal structure that we have everywhere found characteristic of life. This temporal aspect of the moral life is of course evident in discussions of moral progress or development, and Dewey and Tufts emphasize "the dynamic, progressive character of morality" and speak of the moral life as "a moving process, something still in the making ;"9 but it also appears in any adequate analysis of character, for it is impossible to understand a person's character without knowing both his past experience and training and also his purposes and aims, for a man is not only what he has been but also what he is going to be. As a seed is at once the result of the past and the possibility of the future, holding in suspension as it were its potential growth, so moral character may be said both to concentrate the results of its past and to hold in suspension the potentialities and possibilities of its future. As I have suggested before, such descriptions of the temporal structure of life seem to me unsatisfactory, since they attempt to compress the past and the future into the present. Now I think our examination of life has shown the inadequacy of such a conception of temporal structure, though we have not yet found the exact terms in which to describe it. However we see again that life is no instantaneous or momentary affair, for moral life requires both duration and direction.

This brings us to the teleological aspect of the moral life itself in contrast to that of its domain: for the moral life appears to be teleological in two ways. As we have already seen it moves in the realm of values or goods, or of means and ends; in this sense it is related to teleology or value much as mental life is to logical structure or meaning. But, further, the organization of the moral life is teleological in the same sense as are the other types of life that we have examined. That is, moral as well as physical growth or development is progressive and in specific directions. Just what its aim or end is or should be has been the concern of many ethical theories, which have variously described it as happiness, pleasure, self-realization, self-sacrifice, etc., and unsatisfactory and contradictory as these may appear, they agree in pointing to the need of a definite plan of action, guiding principle or life purpose. The difficulty with them seems to be in part at least due to their failure to recognize the need of specific plans for individuals, for they tend to insist upon a general formula for all cases,

9 Ethics, New York, Holt, 1908, p. 4. 
something as though one should try to make all biological organisms conform to a single type. That is, I think that ethical theory should recognize a greater variety of forms of moral life. On the other hand an ethics that would explain moral life wholly in terms of the integration of experience and deny all reference to ends, in avoiding the abstractions of the opposite type, would appear to be self-contradictory if its denial of the teleological aspect of the moral life were taken too literally and uncritically. Thus though Holt scorns an ethics of ends, his quarrel is with final causes as motive forces, while his and Freud's "wishes" are evidently both temporal and teleological and the integrative process that he so warmly advocates as the formula for this ethics "from below" must possess at least as much temporal structure and teleological reference as does organic growth. ${ }^{10}$

Thus the moral life seems to possess the same fundamental features that we have found to be characteristic of the other forms of life that we have so far examined-for like biological and conscious life it is to be defined in terms of an organization that conforms to a definite temporal structure and possesses a teleological reference. Its continuity with these other forms of life is evident and is especially stressed by such writers as Holt and Gilson, who emphasize the importance of reflexes and impulses as the basis of the higher forms of action, and evidently without behavior conduct would be impossible as we could hardly be moral agents if we were not capable of action. Morality also requires consciousness as well as sentiency, for as is commonly recognized an action to be moral must be voluntary and that implies knowledge on the part of the agent as well as the power to act.

The relation between intelligence and morality has been variously construed from that of identity to that of opposition. Erskine has pointed out the Anglo-Saxon distrust of intelligence and glorification of will and character, ${ }^{11}$ while Holt on the other hand would agree with Socrates that wisdom and virtue are one. ${ }^{12}$ The fact of the case would seem to be that the relation of mind and morality varies somewhat with the circumstances and especially with the connection of morality with custom and social tradition. Thus society may extol the good or brave fool in contrast with the brilliant knave and point out that there is no necessary connection between morality and intelligence. On the other hand, if the individual attempts to go beyond mere comformity to tradition and custom and to be truly or rationally moral rather than merely conventional, intelligence appears to be essential.

10 The Freudian Wish and Its Place in Ethics, New York, Holt, 1915.

11 The Moral Obligation to be Intelligent, New York, Duffield, 1916, pp. 4 ff.

12 Loc. cit., pp. 138-140. 
Consciousness and some slight degree of intelligence would seem to be required for morality, but beyond that it appears possible for mental and moral life to develop independently, as is not surprising if the teleological order of things is not identical with their logical structure. Thus some of the best things of life do not appear to be the result of our conscious efforts, and beautiful characters may develop who do not seem to be conscious of their dominant aims, showing that some of the higher as well as the lower forms of teleology may be unconscious. I do not wish to minimize the importance or value of intelligence but rather to suggest that there appears to be a difference, though no discontinuity, between mental and moral life and further that the difference seems to be expressible in terms of the domains in which they occur. 


\section{CHAPTER VI}

\section{LIFE AND SOCIETY}

What may be called social or group life has two quite different though closely related phases, the life of the individual in society and the life of the community itself. In the first case the adjectives appear to describe the type of environment in which the individual life is carried on; thus we speak of the military, political or business life of individuals, contrast a man's family life with his public life and compare the advantages of village and city life. On the other hand the life of a group appears to be something quite different from the life of any or all of its members. The life of a nation or tribe may extend over centuries and wide areas as is perhaps even more evident in the life of a church such as the Roman Catholic. The same of course applies in lesser degree to smaller groups, such as the family, clan, business and political associations, clubs, colleges, armies, special regiments, etc. College life may thus mean either the life of an individual in a special type of environment or the continued life of the college itself.

Fortunately for our present purpose it will not be necessary, I think, to decide the question whether any or all these groups are persons or superindividuals, and whether there is a group consciousness over and above the consciousness of the individuals that compose the group. For all these problems arise mainly in attempts at explanation. The difficulties in dealing with them appear to me to be considerably increased by confusions in the concept of consciousness and by the tendency to identify it with life. Now as we have so often pointed out, our present aim is not explanation, but analysis and definition, so that we are concerned only with the facts of the matter, and nations and other groups appear quite definitely to live as well as sometimes to die, whether or not they are conscious persons. This is hardly surprising; as life does not seem to be identical with or even dependent upon consciousness. It should therefore be possible to examine social life without being drawn into the present controversies as to the nature of the community. ${ }^{1}$

Before going further I may point out that I do not wish to confine

1 Such for example as those discussed by the American Philosophical Association in 1919. For a preliminary presentation see the Philosophical Review, Vol. XXVIII, pp. 547-597. 
our discussion of social life to any one of its forms, but rather so far as possible to include them all. As our discussion of biological life included animal and vegetable, unicellular and multicellular organisms of all sorts, so in considering collective life we are to keep in mind its many varieties, and society and similar words will be used in a very broad sense to cover such various types of communities as clans, tribes, nations, clubs, colleges, business associations, industrial organizations, political groups, churches, armies, etc., etc.-a varied array certainly, but hardly more heterogeneous than the multiplicity of organic forms with which biology deals.

If now we look for the characteristic features of such groups, we find that they all possess a certain amount of organization, which evidently varies a good deal in the different cases. In fact societies are often classified according to the complexity of their structure and the degree of their organization, which is often described in terms of differentiation and integration. Thus the more complex and higher forms of society show a greater differentiation of parts and specialization in the functions of their members or component groups, together with a more perfect and complete organization or integration of these. A well organized army or business perhaps illustrates this even more clearly than the modern state, though Plato's Republic has made it familiar in connection with the ancient city-state, as well as the similarity between society and an animal organism. This comparison is frequently expressed by describing the state or society in terms of organic unity, which may then be contrasted with physical or mechanical unity and perhaps with chemical unity and the differences between them explained by reference to the relative importance of the parts and the whole. ${ }^{2}$ However suggestive this may be for some purposes, our failure in an earlier chapter to distinguish biological organisms from other objects in their environment in terms of their physical and chemical structure, and the discovery that their peculiar organization is due rather to their temporal structure, suggest the probable futility ot trying to understand social organization and life without taking into consideration its temporal structure. McDougall apparently recognizes this when he remarks that "society consists of the dead as well as of the living and the part of the living in determining its life is but insignificant as compared with the part of the dead.'3 This is particularly evident in the case of nations, of the Catholic Church, of tribes and families that preserve their traditions for generations, and to a lesser extent of colleges and universities. That the future as well as the

${ }^{2}$ Cf. J. S. Mackenzie: An Introduction to Social Philosophy, Glasgow, MacLehose, 1890, Chapter III, p. 129.

3 The Group Mind, New York and London, Putnam, 1920, p. 8. 
past is important for social life is emphasized by Royce in his discussion of the nature of communities and in his distinction between communities of memory and of hope. ${ }^{4}$ In other words the organization of society at any time can not be adequately understood without reference to its temporal structure. In this the life of nations and other groups resembles the other forms of life that we have already studied. The great range and extent of the temporal structure of life becomes particularly evident in this connection, since some forms of social life cover centuries, as is evident in the growth of traditions, customs, languages and institutions. In voluntary or purposive groups, the future aspect of their temporal structure is more evident as is also their teleological nature, since they are commonly formed to bring about certain. definite ends as in the case of charitable associations as well as business and industrial organizations. But most groups have both a historical and a purposive aspect and indeed both appear to be important for any adequate community life. Royce in his discussion of the early Christian church emphasizes its need of a past as well as a future reference, and in fact his whole discussion of the community shows its essentially temporal nature. ${ }^{5}$ The importance of both the traditional and purposive features of group life are also very evident in the life of a college $e^{6}$ or an $\operatorname{army}^{7}$ and their traditions are often consciously and carefully cultivated.

The teleological aspect of definitely purposive groups is of course evident, but it seems to be present in other cases as well. For, as we have already seen, natural teleology is not to be identified with conscious purpose and in fact is not dependent upon consciousness. Thus we saw that biological life has a certain teleological aspect and many natural societies seem to be teleological in very much the same way. This appears to be closely connected with the direction of their temporal structure, and to be more correctly described in terms of means and ends or the helping and hindering of tendencies than in terms of conscious forethought and planning. In fact the teleology exhibited in the life of communities may be either conscious or unconscious.

The close interdependence of individuals and society especially in its more fundamental forms is quite evident, for "we can understand the life of individuals and the life of societies only if we always consider them in relation to one another."s Groups of all sorts obviously depend for their existence upon that of individuals, while individuals

4 The Problem of Christianity, New York, Macmillan, 1913, Vol. II, pp. 35-53.

5 Ibid., pp. 35-39.

6 Cf. McDougall: Loc. cit., p. 129.

-Cf. Ibid., p. $7 \mathrm{I}$.

8 Ibid., p. 8. 
in turn owe a great deal to the communities in which they live. " 'In fact, what we call an individual man is what he is because of and by virtue of community, and communities are not mere names, but something real.' Already at birth the child is what he is in virtue of communities: he has something of the family character, something of the national character, something of the civilized character which comes from human society. As he grows, the community in which he lives pours itself into his being in the language he learns and the social atmosphere he breathes, so that the content of his being implies in its every fibre relations of community." 9 In fact without the family, state and some sort of educational and religious organizations, the life of the individual would indeed be "solitary, poor, nasty, brutish and short," for "in such condition, there is no place for industry, because the fruit thereof is uncertain; and consequently no culture of the earth; no navigation, nor use of commodities that may be imported by sea; no commodious buildings; no instruments of moving, and removing such things as require much force; no knowledge of the face of the earth; no account of time; no arts; no letters; no society; and which is worst of all, continual fear, and danger of violent death." 10 Not of course that such a state of affairs ever existed, but it may serve to indicate how much individuals owe to society.

The hereditary group is evidently based on the fact of biological inheritance and emphasizes and extends the dependence of the individual upon earlier forms of life. This has its importance for mental as well as physical life as is evident in the great importance of education, by which the accumulated knowledge and customs of the group are passed on to the individual. A "man without a fellow" thus seems almost as impossible as a man without an ancestor, and it has often been pointed out of late that the development of self-consciousness is probably due to comparison and contrast with our fellows, since it is through their attitudes toward us and ours toward them that we come to know both them and ourselves. ${ }^{11}$ McDougall evidently has the same point in mind when he emphasizes the need of contrasting and rival groups for the full development of the "group mind." 12

It is hardly necessary to point out that at the present stage of civilization human individuals depend upon their social environment not only for most of the necessities of life but also for many of its

9 E. Barker: Political. Thought in England from Herbert Spencer to the Present Day, New York, Holt (Home University Library, No. 98), pp. 62, 63. 10 T. Hobbes: Leviathan, Part I, chapter I3.

11 Cf. J. Royce: Loc. cit., Vol. I, pp. 129 ff. Also E. A. Singer, Jr.: "Man and Fellow-Man," Journal of Philosophy, Vol. X, pp. I4I ff.

12 Loc. cit., pp. 226 ff. 
values and ideals. This is so true of the moral life that discussions of primitive morals consist largely in a description of primitive social customs and institutions, and in fact much of the importance and significance of moral life is due to its social setting, for many of the virtues would be impossible or meaningless unless men lived and worked together and without social relationships human life would be poor indeed, for friendship and love as well as rivalry and competition would be gone. The religious life also has quite definitely social aspects and discussions of primitive religions as of primitive morals, not only emphasize these but seem to make religion wholly a social affair. With the more developed forms, it is common to distinguish between the religious experience of individuals such as James describes in his Varicties of Religious Experience and the social aspect of religion as expressed in organized churches. We shall consider the religious life as a form of the spiritual life in the next chapter, but we may here note not only that churches such as the Roman Catholic evidently possess a type of life very similar to that of nations and states, but also that most forms of religion have a social as well as a personal aspect. Thus again is the continuity of the different forms of life brought to our attention. Though society may be conceived as an ideal we have not attempted to discuss it here as such but have left such a consideration of it for the next chapter and have confined ourselves in the present one to an examination of society or rather of a multitude of different types of groups and associations as facts and have simply inquired into the nature of social life as it exists.

Our discussion of social life, both as the life of society and as that of the individual in society, has shown the same fundamental features to be characteristic of these types of life as we have previously found in the case of the other forms of life that we have examined. All forms of group life were found to possess some definite organization, however much this might vary in different cases, and it was further discovered that this organization could be understood only in connection with its temporal structure and teleological reference. Here we found the temporal aspect of life particularly prominent, as the growth of customs and language as well as the importance of history showed the great extent and range that its temporal structure must cover. In the case of the individual this was especially emphasized by the importance of education. On the other hand the teleological aspect of life is less obvious here than in the moral life and appeared to resemble in some cases that found on the biological plane, being frequently unconscious, though of course with some types of association it becomes more evident and deliberate. 


\section{CHAPTER VII}

IDEALS AND THE SPIRITUAL LIFE

So far we have been concerned with what might be termed the various forms of natural life, though in the last chapters especially our attention has been directed to certain ideals toward which some aspects of life seem to point. I therefore propose now to examine life as it appears in connection with these ideals. The moral life can be considered from this angle, e.g. when it appears as the worship of an absolute good; and perhaps the categorical imperative belongs here as well, as it seems out of place in the naturalistic ethics that we discussed in a preceding chapter. However that may be, it is quite possible to conceive the ends or aims of the moral life in ideal terms, and similarly society or humanity may appear to be an ideal rather than a fact. Thus though the religious life perhaps stands out as preëminently connected with the ideal, the true or the beautiful may sometimes take the place assigned by religion to God, and the intellectual or contemplative life and the esthetic or artistic life appear as aspects of the spiritual life.

Our discussion of the spiritual life will thus have to be very general and confined to an examination of its fundamental characteristics without any attempt at exposition or evaluation of its many forms. For we are not here so much concerned with special philosophies of life or the various answers that have been given to the question of its meaning and value, as we are to get clearly before us the subject matter with which these theories deal. For as I have had occasion to point out before, I am not attempting to explain or evaluate life, but simply to examine some of its forms with the hope of discovering its nature. Thus the aim of the present chapter is limited to a portrayal of the characteristics of the spiritual or inner life and our interest in the many interpretations of it is quite secondary and entirely limited to what light they can throw upon its nature. Though most of the discussions of this form of life are primarily concerned with an interpretation or evaluation of it, I hope nevertheless that it will be possible to make clear the subject matter itself and so get before us a picture of life at this level as well as at the others that we have considered in the preceding chapters.

As has been suggested already, I intend to deal with a great variety of related forms of life. The inner life is commonly recognized to 
possess several aspects: Gilson names the intellectual, esthetic, moral and religious, and Santayana discusses the Life of Reason in society, religion, art and science as well as common sense. The religious life appears in many forms such as the ascetic and saintly, the mystic and unitive lives, and also as a life of love, faith, loyalty or piety, and the various religions and sects each offer their theories of life and try to lead their disciples to a fuller, richer, better or more abundant life. We are thus concerned with many forms of what may be called in general personal life or the life of the spirit. Certain aspects of this have been touched upon in the preceding chapters: we have had occasion to note the social aspects of the religious life in particular, while the close connection between moral and spiritual life is too evident to require comment. This serves to show again the continuity of life in its various forms despite the obvious differences in the realms in which it moves.

As the religious life is the most commonly recognized and discussed form of the spiritual life, we may well begin our examination with it. However much religions may differ in many respects, they agree in giving us "another world to live in." How this other world is conceived, of course, varies greatly with different religions and might to a large extent be used to differentiate them. But however that may be, the spiritual life appears to move in a realm very different from those in which we found the types of life already examined. Just how this new world is to be defined seems far from clear, and it is not my present aim to defend any particular conception of it, for it is life and not spirit that we are considering. We may content ourselves therefore with saying that the religious life moves in a spiritual realm, while the various forms of worship, sacrifice and prayer help one to maintain or regain contact with it. Naturally most of the interest in discussions of religious life have thus turned upon the nature of God and spirit, of the joys of living in this wonderful world and of the means of reaching it. Religious life as the saintly or ascetic or mystic life, and even more in its aspects of the future or eternal life, may thus come to be regarded as moving in a realm quite apart. But in its more common forms religious life is clearly continuous with the other types of personal life. Gilson can thus refer to religion as the superior hygiene of personality ${ }^{1}$ and call it the maker of men or producer of personalities. ${ }^{2}$ So conceived religion gives meaning and value to life. It furnishes the individual with a pretty coherent view of the world and an idea of what his life in it should be. In Santayana's

1 "Essai sur la vie intérieur," Revue Philosophique, Vol. LXXXIX, p. 52.

2 Ibid., p. 55. 
words it gives him spiritual nationality, 3 and defines the meaning of life for him so that Gilson says that to deprive a man of his religion in order to set him free is like freeing an animal of its skeleton and nervous system. ${ }^{4}$ Or more baldly put, our personal life as well as our physical life must have specific form, for in Gilson's words, to be is to be determinate. ${ }^{5}$

Though the religious life may be regarded as the most complete and perfect form of the spiritual or inner life, other forms are to be considered as well. Gilson emphasizes the esthetic and moral aspects and in a different category the intellectual. These evidently have close connections with the types of life that we have examined in the preceding chapters. Sentient life may be regarded as the natural basis of the esthetic and artistic life; thus Gilson calls art a hygiene of sensibility, ${ }^{6}$ and emotion as well as sensation appears to be essential for both artistic creation and esthetic appreciation. Thus Noyes says, "a work of art is the statement of the artist's insight into nature, moulded and suffused by the emotion attending his perception,"' "it is not thought that constitutes appreciation; it is emotion."8 But the artistic and the esthetic life are evidently not identical with sentient and emotional life, for the latter in many cases appears unconnected with art, while in all art we go beyond mere sensation and emotion. For art requires and expresses a special type of selection and organization of elements not peculiar to it. Thus both sentient and esthetic life in a sense move in a world of sense qualities, but they perceive objects with such different interests that art appears to transform this world. The difference may be most briefly indicated by referring it to beauty, thus suggesting the importance of the ideal for the esthetic life. Or more concretely, sentient and emotional life views its world quite naturally in relation to itself, while for artistic and esthetic life the same world is significant only because of its inner meaning and harmony. Perhaps this difference is more commonly stated by regarding the one as a bodily and the other as a spiritual function or activity. This may be a very suggestive and satisfactory mode of statement if it is not understood, as is sometimes the case, as implying the discontinuity of these forms of life.

A very similar connection may be noted between conscious or mental

3 The Life of Reason, New York, Scribner's, 1916, Vol. III, p. 5.

4 Loc. cit., p. 54.

5 Ibid., p. 42.

6 Ibid., p. 50.

TThe Gate of Appreciation, Boston, Houghton Mifflin Co., 1907, p. 241.

8 Ibid., p. 35. 
life as it was discussed in Chapter. IV and what may be termed intellectual or speculative life. Both evidently move in the domain of logical structure, while differing considerably in their attitude toward it. Thus one may come to worship and serve truth in a truly religious fashion as did the hunter in Olive Schreiner's dream, or he may be rather polytheistic in his intellectual devotion and recognize many forms of truth; but in any case the ardent seeker for truth, whether monistically or pluralistically conceived, seems to be living in a world quite different from that described in connection with conscious life, and here again the difference seems to be expressible only by reference to the ideal.

In like manner the good may be conceived as an ideal rather than a fact, and thus be treated religiously rather than morally. The distinction here is probably less generally and clearly recognized than in the two previous cases, for the division here may be regarded as coming within the moral life rather than in the contrast between the moral and religious aspects of the inner life. But in whatever terms it is expressed and whether values and ideals be identified or contrasted, there seem to be two very different attitudes toward them. If value is defined as in the preceding chapters in terms of use and tendency, then ideals seem to take us into a new realm or dimension of being, which of course is sometimes described in terms of value and may then be contrasted with its more practical aspects. In other words the ideals that we are now considering appear to be quite different from the type of value that we have elsewhere discussed in terms of means and ends. For one thing those values were to be used and employed, while ideals appear rather as the objects of love and service.

Among these ideals God and society may also be included. Of course both may be treated as facts as well and we have attempted to present such a discussion of society. But that it may be an ideal also is shown, I think, by the fact that it may be treated as an object of religious devotion and as such served. Thus Comte tried to institute a religion of humanity; and in some of our churches to-day social service of one sort or another seems to take the place of what was once regarded as the truly religious office of the church. Royce's emphasis upon the "beloved community" in his discussion of the Problem of Christianity may be regarded as an attempt to interpret the present social interest of religion in terms of Christian dogma and he certainly treats the community as an object for loyalty and devotion in a quite religious fashion. Similarly God may be conceived as an ideal rather than as a natural fact, but the God that means the ideal of life is not to be identified with the God which means the forces of 
nature. ${ }^{9}$ The opposition that the former conception often arouses is due $I$ think to a feeling that ideals are less real than facts or that they are merely subjective. Would any one object to God being called ideal in the Platonic sense? For is not this just the way that he is most adequately conceived? And in this sense are not ideals more truly real than anything else? In such a discussion real is apparently a value rather than an existential category. But we are not at present undertaking to defend any particular theory of the nature of ideals, but rather to examine the spiritual life as it is lived in their presence.

For as sentient life moved in a world of sense qualities, mental life in one of meaning and implication, and moral life in one of means and ends, so the spiritual life is lived in the presence of ideals. Life thus comes to move in a world where things are beautiful as well as pleasant and useful; truth may be loved and sought for its own sake and society be an ideal to be served as well as an environment in which one lives. In other words the world possesses an ideal dimension and it seems to be on this plane that our spiritual life occurs, for in Santayana's words "man is spiritual when he lives in the presence of the ideal." 10

Before proceeding to a more direct analysis of the spiritual life it may be well to pause for a brief parenthesis on the domains or planes of being to which reference has been so frequently made. The comparison with a layer cake, in which each plane rests upon the one below it, though perhaps the readiest to hand does not appear to be accurate, as it would arrange them in a hierarchy in which each level would rest upon the preceding one and thus appear to be dependent upon it. But this does not seem to be the case: for example we saw that value does not appear to be dependent upon consciousness, as such a scheme would seem to require. Now it seems to me that the realms or planes of being that we have had occasion to consider, could be more accurately likened to the various types of ether waves, such as those of light, heat and wireless telegraphy, which pass through the same space without confusion or interference, using the same material while each preserves its specific identity. Similarly concrete things conform to different structures or orders in a perfectly simple and natural manner. Thus the river which conforms to mechanical and chemical structure, may also possess meaning in so far as it enters into logical structure, and may further possess value as it serves for tran:portation or irrigation, and finally it may appear as a special expression or embodiment of beauty and possibly even be worshipped as a god.

- Cf. G. Santayana: Loc. cit., Vol. III, p. 169.

10 Ibid., Vol. III, p. 193. 
There then appears to be no discontinuity between the ideal and the natural and Santayana insists constantly that every ideal has a natural basis while all natural processes have ideal fulfillments. Similarly the spiritual life is continuous with the other forms of life and the inner or personal life may be understood to include some of the types discussed in earlier chapters as well as those considered in the present one, while human life may evidently move in all the realms or planes of being that we have considered. Thus the terms "person" and "self" may be used with very different extensions as James has so well pointed out in connection with the self, for "in its widest possib!c sense, however, a man's Self is the sum total of all that he can call his, not only his body and his psychic powers, but his clothes and his house, his wife and children, his ancestors and friends, his reputation and works, his lands and horses, and yacht and bank-account." 11 In other words the self lives on the physical, mental and social planes as well as on the spiritual, and although James's introspective analysis did not show him a purely spiritual element, ${ }^{12}$ it was apparently because he looked for it among sensations. In a similar fashion Hume failed to find any self at all and James later came to question the existence of consciousness. ${ }^{13}$ Now the conclusion to be drawn would seem not to be the one commonly adduced, namely that spirit or self or consciousness does not exist, but rather that the methods used in investigating them were at fault. In fact psychological methods appear to be better adapted to an investigation of sentient than of spiritual life.

But at present our primary concern is with the spiritual life, which we have seen moves in a much richer and more inclusive world than does sentient life, for the ideal as well as the natural is important for it. When now we try to see just what are the fundamental features of the life of the spirit, we find them to be essentially the same as in the other forms of life we have examined, the differences in all cases being due to the nature of the environment in which life is found and not to the nature of life itself, which seems to be everywhere the same. Thus the organization characteristic of personality is often described in terms of selection and assimilation, as for example by Gilson, or of discrimination and integration, as by Holt; while for an adequate understanding of it, it is necessary to take account both of its temporal structure and teleological reference. Royce of course stresses the purposive aspect of the individual self and also emphasizes the neet of a

11 Psychology, New York. Holt, 1899, Vol. I, p. 291.

12 Ibid., p. 300.

13 See "Does Consciousness Exist?" Essays in Radical Empiricism. New York, Longmans, Green \& Co., 1912, pp. I-38. 
coherent plan in the religious life as well as elsewhere. ${ }^{14}$ This he very definitely connects with the temporal structure of personal life: in his own words, "a self is, by its very essence, a being with a past," 15 and "my idea of myself is an interpretation of my past,-linked also with an interpretation of my hopes and intentions as to my future,"16 also "our idea of the individual self is no mere present datum or collection of data, but is based upon an interpretation of the sense, of the tendency, of the coherence, and of the value of a life to which belongs the memory of its own past." 17 Though some of the phrases here are suggestive of a particular philosophical theory, they none the less indicate very clearly certain important features of the personal or spiritual life. The future aspect of its temporal structure is brought out especially well, I think, in Fosdick's discussion of "Faith and Life's Adventure."18 For example he describes life as "a continuous adventure into the unknown,"19 demanding insight and daring,"20 and further says, "if one tries to imagine the world with all faith gone-knowledge supposedly having taken its place-he must conceive a world where no conscious life and effort remain at all." 21 In other words it is impossible to conceive our personal and spiritual life without reference to temporal structure.

The teleological aspect of life is also especially prominent here in connection with ideal aims and ends. Thus while the personal life may possess a great variety of purposes, which indeed could be used to distinguish some of its different forms or types, in its more generally recognized spiritual forms these usually are quite definitely connected with ideals of some sort or another. Thus the spiritual, like the other forms of life, is seen to possess a characteristic organization which can be adequately expressed only in terms of its temporal structure and teleological reference.

14 Cf. The Problem of Christianity, Vol. II, pp. 3-4.

15 Ibid., p. 40.

16 Ibid., p. 42.

17 Ibid., p. 43.

1s The Meaning of Fuith, New York, Association Press, 1921. Chapter I.

19 Ibid., p. 3 .

20 Ibid., p. 13.

21 Ibid., p. 17. 


\section{CONCLUSION}





\section{CHAPTER VIII}

\section{DEFINITION OF LIFE}

The preceding examination has shown that life possesses the same fundamental features wherever it is found and that the great multiplicity and variety of its forms-which at first appeared so confusing as to make us almost despair of finding any common terms in which to define it-is the result of its occurring in so many different realms. Life can therefore be defined in terms of these common features, namely organization, temporal structure and teleology, and it will not be necessary to give one definition of the spiritual life and another of physical life, etc. However, the fact that life is fundamentally the same everywhere does not necessarily imply that it is a simple or ultimate category nor that each of its elements or factors is always of the same relative importance: thus in some connections its organization is most emphasized, in others its temporal structure is more evident or again its teleological aspect may be more prominent. Not only do these features of life vary in the relative emphasis that they receive, but they are also curiously interrelated in ways that require further investigation before the final formulation of a definition of life.

Perhaps the most obvious characteristic of living beings is their type of organization, so that life is sometimes conceived in terms of organic unity. On the biological plane, the individual organism appears to be the result of selection and assimilation of material derived from its environment; for the biological organism is composed of the same elements as other things in its domain and is differentiated from them by the mode of its organization, which, though describable in terms of differentiation and integration, can be adequately defined only by reference to its temporal structure and teleological aspect. The psychological organism is often described as an integration of simpler components, and mental life evidently requires a discrimination and organization of meanings. On the moral and spiritual planes the development of the inner life proceeds by a process of selection and assimilation. In fact organization is quite as evident here as on the biological plane and much of the discussion of the moral and spiritual life deals with the question of the manner in which this organization is to be obtained. Here its teleological aspect is particularly evident, but, as progressive, it requires temporal structure as well. 
Turning then to the consideration of temporal structure, we have seen that life everywhere implies growth and development, whether of organism, consciousness, character or personality; thus life is always a process even if at times it does not appear to show progress as well. It exists in time in something the same way that matter exists in space: that is, life is essentially temporal. This is evident I think in all its varieties; it is especially emphasized when life is identified with one's career or the duration of an activity as when we speak of the "life" of a motor. Though this latter figurative expression only emphasizes the fact that life has a temporal aspect, the examination of its more essential forms has shown that it possesses temporal structure as well. Thus we saw that organisms not only grow and develop, but also that their very nature and character can be understood only in terms of their history and future: an acorn is not only so much matter of a certain mechanical and chemical structure, it is also so much growth of a special kind as well as the result of past growth. And not only organic forms but protoplasm itself seem to be dependent upon their temporal structure as well as upon their spatial structure and chemical composition. By reference to these latter features alone it seemed impossible to adequately differentiate living organisms from the inorganic world in which they are found, for protoplasm contains no unique chemical element, nor can living beings be defined in spatial or mechanical terms in such a way as to clearly separate them from physical forms that are not alive. Its temporal structure however does seem to definitely distinguish physical life from its environment.

The temporal structure of life is perhaps even more evident on what we called the plane of sentiency for want of a better term. The behavior of the organism at any time depends upon its past experience and history, as well as upon the present situation in which it finds itself. The future aspect of behavior is of course most obvious in purposive action, but its presence elsewhere is evident and will be more readily recognized when it is not confused with the question of consciousness. Though the temporal aspect of emotional life is perhaps not so obvious as that of instinctive and impulsive life, its importance is none the less readily seen when it is realized how important are not only our own pasts but probably those of even our remote ancestors in determining the character of our emotions at any time, and the same is probably true, though perhaps to a less degree, in the case of sensations. The future reference of both emotion and sensation is evident in their relation to the activities of various sorts that depend upon and follow from them.

With mental life these processes become conscious, the past is re- 
tained in memory and the future is planned and hoped for, and the effectiveness of the past and future is clearly recognized. This is evident in varying degrees and extensions. All our knowledge, however momentary or eternal it may seem, appears to be understandable as it occurs in definite and individual form only by reference to our pasts and futures: in Carr's words, "all cognition is recognition" and the pragmatists are also right in emphasizing the future reference of all consciousness. This does not necessarily imply that mind in the metaphysical sense evolves or that truth is not eternal; but only that knowledge as it occurs in mental life is dependent upon the temporal structure of life, just as the physical form and chemical composition of the biological organism depend upon the temporal structure of life as it is found on the physical plane. In other words, though logical. mechanical and chemical structures are quite independent of temporal structure, their definite forms in connection with life do depend upon its temporal structure. Or we may say that life is essentially temporal and that while each of its various types conforms to the structure of the realm in which it occurs, everywhere living beings can be understood only in connection with their temporal structure. Thus any attempt to explain them wholly in terms of the domains in which their temporal structure is worked out, inevitably results in a failure to differentiate them from non-living things within the same domain.

The examination of social life only made more clear its temporal aspect by exhibiting it in more extended form and wider range in connection with history and education and in the formation of communities of memory and of hope.

Growth and development were also found to be important characteristics of the inner, moral and religious life as well as of physical life. Spirit may be permanent and unchanging and ideals eternal and immutable, but the spiritual life requires the progressive organization and expression of them. This is perhaps most commonly recognized in connection with the development of character and personality; for not only do we hope for progress here, but what we are at any time is a function of both our past and future, of our memories and experiences, of our purposes and hopes.

Thus life not only extends through time in the same way that physical objects exist for varying periods of time, but it possesses a peculiar temporal structure that differentiates it both from them and from eternal realities. It seems to be particularly difficult to make clear the exact nature of this structure, perhaps because of our tendency to spatialize time as Bergson has so eloquently urged. The difficulty seems to be due to a number of causes some which Bergson has stated 
and some of which appear to be very different from those that he has most emphasized. For one thing I have urged that our difficulty in understanding the nature of temporal structures is due partly to the fact that we have treated them from too practical a standpoint and have not accorded them the independent investigation that has made us so familiar with the variety of spatial structures. On the one hand time has been treated only as it appears in connection with physical nature. It there resembles space in being a mode of separation between things or events and is conceived as a succession of instants or simultaneities. Its parts are all alike and in themselves quite indistinguishable. In this way time has figured as an independent variable in the equations of physics. So science has dealt rather with durationless instants than with temporal structure and when time has been thought of as having any structure it is commonly compared with a line as a one-dimensional series. It is this spatialized time that Bergson contrasts with duration which he tends to identify with life. I think that he is quite right in maintaining that what we have been terming the temporal structure of life is very different from time as it appears in the physical sciences. But his discussions of duration seem to me to be dominated too much by practical and immediate interests to be wholly clear in a technical and metaphysical sense, for the treatment of temporal structure wholly in terms of past, present and future is too much like trying to develop a geometry in terms of here and yonder or of in front, behind and beside with reference to the point at which we happen to be. I am not questioning the possibility or the value of such distinctions but only suggesting that if such a basis had been insisted upon, our knowledge of spatial structure might be in as elementary a state as is our knowledge of temporal structure and we might find ourselves quite as much at a loss for adequate terms in which to describe spatial structures as we now do for temporal ones.

Now with a full recognition of the difficulties before us, let us try to make as clear as possible the nature of the temporal structure that appears to be characteristic of life. It is most naturally expressed, if we use the terms of the common distinction of past, present and future, by saying that life unites or transcends them, or that it makes the past and future effective in the present. But this. immediately gets us into trouble, for how can past and future be present and if life transcends the distinctions of past, present and future, does it not cease to be temporal? This not only emphasizes the inadequacy of the terms at our disposal for a description of temporal structure, but indicates as well how quickly an attempt at analysis and definition runs over into questions of explanation. As the aim of the present examina- 
tion is not explanation but definition, we need not attempt to explain how the past can be preserved in the present, nor how the future can be effective now. What I do wish to make as clear as possible is that life possesses a temporal structure that is not confined to the moment. In Montague's words "action at a distance in time" is characteristic of living beings as well as "action at a distance in space," and this quite regardless of how these are to be explained and whether or not it is necessary to suppose connecting media through which effects can be propagated. But temporal structure is not to be confused with activity or movement, it being no more productive or effective than spatial or other structures, all of which are merely the inert principles to which all activity conforms, while all efficacy resides in concrete and individual things. That these may operate in complex temporal as well as spatial structures is especially evident in the case of living beings for whom things distant in time may be quite as real and effective as things distant in space. Indeed living things may be said to extend in time as physical things extend in space and the operations of the former conform to temporal structure as those of the latter do to mechanical structure.

Whether life is to be identified with temporal structure or rather with a special kind of temporal structure is not clear, as the conceptions of time and temporal structure have not yet been adequately considered. An examination of all kinds of temporal structure is obviously beyond the range of the present paper; we may however point out some of the characteristics of it as it appears in connection with life. As has already been noted, the growth and development so characteristic of life clearly indicate its temporal aspect and show that life transcends the moment-that life can not be compressed into an instant. Every attempt to understand the characteristics of living forms as they appear at any time requires reference to both their pasts and their futures. On the mental plane this is very evident in memory, purpose, anticipation and hope; consciousness does not appear to create this temporal structure, but rather to recognize and utilize it. In fact temporal structure seems to be characteristic of life rather than of consciousness. Of course the same individuals may be both conscious and living, but that is only the more reason for not confusing the categories of life and mind. It is the failure to make this distinction, I think, that is responsible for a great part of the confusion that has attended the discussion of each of them. If mind can be defined in terms of logical structure and life in terms of temporal structure, it should be possible to distinguish the two and avoid the confusion that has naturally resulted from an unconscious blending of such different categories. 
But returning to our examination of temporal structure, we may note that in connection with life it appears to be closely related to teleology, while in the physical world time is often considered in connection with causation. In fact it is possible to conceive teleology as the future aspect of temporal structure, while there is certainly a tendency to conceive past time in causal or at least deterministic terms. The future would then appear to be radically different from the past and if teleology and causality are taken as opposite and conflicting categories, it is not surprising that the attempt to express past, present and future in the same terms is productive of so little but confusion. If the past is the realm of the irrevocable, the future that of possibility and the present that of efficacy and actuality, there is little wonder that they can not be arranged in a simple one-dimensional series, and it might be well to recognize that the past, present and future are distinct dimensions of time. But such a distinction can be maintained only by reference to the present, which is too variable and practical to form a satisfactory basis for an adequate conception of temporal structure. This also seems to be the reason for much of the difficulty we have in conceiving events as they pass from future to past, and what was considered to be teleological and free is described in terms of causality and necessity. It is evident then, if temporal structure is to be expressed in terms of past, present and future, these can not be reduced to a single dimension. But $I$ have been urging that it should be possible as well as desirable to find more adequate and serviceable terms in which to describe time, for past, present and future are united in temporal structures, if not in a single dimension, and the distinction between them seems to be a practical and existential affair that should conform to temporal structure rather than define it.

However closely teleology and temporal structure may seem to be connected, they are hardly to be identified, I think, for though the distinction of means and ends points to the future, it implies more than temporal structure, as "the definition of natural teleology involves the recognition that uses are specific, in specific and controlled directions, and of comparative value in view of these directions." 1 In fact it is generally recognized that teleology requires reference to value as well as to time. But unfortunately recent discussions of value, which are amongst the most perplexing and unsatisfactory of those of contemporary philosophy, seem to have been generally confused by the introduction of epistemological and psychological material, which has befogged the subject of investigation and raised unnecessary questions, largely in connection with the relation of consciousness and value. That

1 Woodbridge: "Natural Teleology," p. 322. 
teleology is not dependent upon consciousness seems evident; our examination of life has shown the presence of use and adaptation on the physical plane as well as upon others, and Woodbridge and Henderson agree that teleology is found in inorganic nature also though their treatments of it differ widely. Now as physical nature is admittedly mechanical, this recognition of its teleological aspect might be regarded as implying a conflict between the two; but I think that the situation is much better described when mechanism and teleology are recognized as categories of different levels as suggested by Haldane in his use of the terms lower and higher, ${ }^{2}$ or in others words that there is no contradiction involved in anything being both mechanical and teleological so long as the fundamental distinction between them is not forgotten: that is, use has nothing to do with causation- "if a thing is useful, it is useful irrespective of the causes that produced it." 3

Now our examination of life has shown that teleology occurs on other planes of being than the mechanical and is present in all types of life as well as in inanimate nature. It is found in the biological realm in connection with growth and development, becomes more obvious in behavior, is generally recognized in the domain of consciousness as purpose, and becomes highly significant in the field of morals as design, while in the spiritual realm ideal ends and aims become important. Thus we find life presenting a teleological aspect at all its levels, for the distinction between means and ends is always important for it and it everywhere seems to require organization with reference to specific ends, though the nature of these ends varies with the different types of life. In fact much that is written about the moral and spiritual life concerns the problem of what ends should be chosen, and the question of the meaning and value of life evidently centers in its theological aspect and is usually answered in terms of its organization with reference to particular ends.

Life, then, possesses an organization that is temporal and teleological, so that it may be defined as that type of organization which possesses temporal structure and teleological reference or more graphically as individualized temporal structure. But suggestive as this latter definition is, it does not appear to be wholly adequate, as there seem to be other forms of temporal structure, such as those characteristic of music and of the history of non-living things like the earth's crust. Further differentia of life therefore seem to be required and unfortunately we do not know enough about temporal structure to be able to find them in terms of its different kinds. We shall therefore

2 Cf. Mechanism, Life and Personality, New York, Dutton, 19r4, pp. 95-99.

3 Woodbridge: Loc. cit., p. $3 \mathbf{1} 3$. 
have to look again to our analysis of life to get its further characteristics. We have seen that life processes have a teleological as well as a temporal factor: they are in specific directions and definite ends are attained through a variety of means. Life means progress as well as accumulation, and growth and development possess a teleological reference as well as a temporal structure. Thus Singer would define life as purposive behavior.

As we have already seen, the teleological and temporal aspects of life are very closely connected but the exact relations between them are far from clear. Teleology is sometimes identified with the future portion of temporal structure, or taken as the defining characteristic of the future dimension of time. But though the distinction of means and ends points to the future, it hardly seems to be identified with it. If value were not such an uncertain and controversal term, it would be natural to say that teleology differed from temporal structure primarily because it implied reference to values. The distinction is probably less ambiguously stated by defining teleology in terms of the distinction of means and ends, which, though conforming to temporal structure in their operation, would not serve to define it.

We have further seen that while all life is teleological, ends vary greatly with the different types of life. The development and maintenance of specific form is most in evidence on the biological plane, while behavior seems to be directed toward a great variety of ends generally connected with the preservation of the organism or the species. With consciousness a greater range of ends becomes possible, and the moral life is so concerned with ends that morality has been called "the realm of ends," while with the spiritual or inner life ideal ends are sought. Means as well as ends naturally differ with the different types of life, as they have to conform to the structure characteristic of the realm in which it moves. Thus on the biological plane life attains its ends by the use of means that conform to the mechanical and chemical structure of that domain, and similarly on the other planes as well, living beings conform to the structure of their environment. In fact life seems always to make use of elements derived from its environment as the means for obtaining its ends. In this sense it may be said to be continuous with its environment or the realm in which it is moving. But attempts to define any of its many forms wholly in terms of those domains fail to differentiate them from other objects found therein, since the essential characteristics of life are not limited to any one of the planes on which it occurs but cuts them all, so that different types of life appear to be continuous with each other. Thus there appears to be no break between physical and sentient life, 
nor between sentient and mental life, while the moral and spiritual lives are continuous with mental life and social life is possible only because of the existence of individual life of various types.

In conclusion we may note that the individuality and activity, so evidently characteristic of living beings in all realms, are due to the fact of their particular and concrete existence and do not appear to be a defining characteristic of life. Their activities conform to the temporal structure of life as well as to the structures of the different domains in which its various forms occur. The individuality of living things seems to be the result of the particularization of the organization characteristic of life, an organization that we have seen is dependent upon temporal structure and teleological reference. Life thus seems to be definable ultimately in terms of temporal structure and teleology, but an adequate picture of it would also include reference to the different realms in which it occurs. It is then seen that each type of life is continuous with its domain and can be conceived as a particular organization of elements derived therefrom, by a process of selection and assimilation, of differentiation and integration, but a careful analysis of this organization shows that it is dependent for its characteristic form upon the temporal structure and teleological reference of life. 


\section{SELECTED BIBLIOGRAPHY}

Aristotle: On the Parts of Animals, trans. by W. Ogle. London, Kegan Paul, Trench \& Co., 1882 .

Bergson, H.: Creative Evolution, trans. by A. Mitchell. New York, Holt, I9II.

"Life and Consciousness," Hibbert Journal, vol. Io (pp. 24-44).

Bosanquet, B.: The Principle of Individuality and Value, 1912.

The Value and Destiny of the Individual. London, Macmillan, 1913.

Brooks, W. K.: The Foundations of Zoölogy. New York, Macmillan, I899.

DrIEsCH, H.: The Problem of Individuality. London, Macinillan, I9I4.

The Science and Philosophy of the Organism. London, Black, I908.

Gilson, E.: "Essai sur la vie intérieure"; Revue Philosophique, vol. 89 (pp. 23-78).

Haldane, J. S.: Mechanism, Life and Personality. New York, Dutton, 19r4.

Organism and Environment. New Haven, 1917.

Henderson, L. J.: The Fitness of the Environment. New York, Macmillan, I9I3.

The Order of Nature. Cambridge, Harvard University Press, I9I7.

Holmes, S. J.: The Evolution of Animal Intelligence. New York, Holt, I9II.

Hour, E. B.: The Freudian Wish and its Place in Ethics. New York, Holt, 1915 .

James, W.: The Varieties of Religious Experience. New York, Longmans, I9I1.

On Some of Life's Ideals. New York, Holt, I900.

Jennings, H. S.: Behavior of the Lower Organisms. New York, Columbia University. Press, I906.

Johnstone, J.: The Philosophy of Biology. Cambridge, University Press, I914.

Loeв, J.: Forced Movements, Tropisms and Animal Conduct. Philadelphia and London, Lippincott, 1918.

The Mechanistic Conception of Life. Chicago, University Press, I9I2.

The Organism as a Whole. New York, Putnam, I9I6.

MícDougall, W.: Body and Mind. London, Methuen, 1911.

The Group Mind. New York and London, Putnam, I920.

Montague, W. P.: "Consciousness a Form of Energy"; Essays Philosophical and Psychological in Honor of William James. New York, Longmans, 1908.

Pearson, K.: The Grammar of Science. London, Black, 1900.

Prtkin, W.: "Some Realistic Implications of Biology"; The New Realism. New York, Macmillan, 1912.

Ritrer, W. E.: The Unity of the Organism. Boston, Badger (Gorham Press), I9I9.

Royce, J.: The Problem of Christianity. New York, Macmillan, 19I3.

Russell, B.: "On the Notion of Cause"; Proceedings of the Aristotelian Society, vol. XIII (pp. I-26).

Santayana, G.: The Life of Reason. New York, Scribner, 19I6.

SCHÄFER, E. A.: "The Nature, Origin and Maintenance of Life"; Scientific American Supplement, vol. LXXIV.

Sheidon, W. H.: "An Empirical Definition of Value"; Journal of Philosophy, vol. XI (pp. II3-I24). 
Singer, E. A., JR.: "The Pulse of Life"; Journal of Philosophy, vol. XI (pp. 645-655).

SPENCER, H.: The Principles of Biology. New York, Appleton, 1904.

Troland, L. T.: "The Chemical Origin and Regulation of Life"; Monist, vol. XXIV (pp. 92-133).

WARren, H. C.: "A Study of Purpose"; Journal of Philosophy, vol. XIII (pp. 5-26, 29-49, 57-72).

Washburn, M. F.: The Animal Mind. New York, Macmillan, 1917.

WoODBRIDGE, F. J. E.: "Natural Teleology"; in Essays in Modern Theology and Related Subjects. New York, Scribner, igri.

"Consciousness, the Sense Organs and the Nervous System"; Journal of Philosophy, vol. VI (pp. 449-455).

"Structure"; Journal of Philosophy, vol. XIV (pp. 680-688). 


\section{VITA}

I, Florence Webster, was born in Haverhill, Massachusetts, on February 14, 1889. My father is George H. Webster, my mother, Mary Etta (Gardner) Webster. I was graduated from the Haverhill High School in 1908. Entering Wellesley College that autumn, I received its B.A. degree in 1912, having attained the rank of Durant scholar and had been elected to Phi Beta Kappa (in 1911). I continued the study of philosophy under the direction of Professors Mary W. Calkins and Mary S. Case at Wellesley during the next two years and acted as graduate assistant in the Department of Philosophy and Psychology in the second year (1913-14). I also attended a seminary at Harvard University each year: the first in ethics conducted by Professors George H. Palmer and Ralph B. Perry, the second in logic under Professor Josiah Royce. In November 1914, I received the M.A. degree from Wellesley College, with philosophy as my major subject and mathematics as a minor.

During 1915-16, I studied at Columbia University, attending courses in philosophy given by Professors F. J. E. Woodbridge and John Dewey and in mathematics by Professor Cassius J. Keyser. The following year I attended Professor R. F. A. Hoernlé's seminary in metaphysics at Harvard University and in the winter of 1919 a course in mathematical logic given there by Dr. Henry M. Sheffer. Returning to Columbia University in the fall of 1919, I continued work upon my dissertation there until February 1921 and attended classes conducted by Professors F. J. E. Woodbridge, W. P. Montague, J. H. Tufts and Dr. Helen H. Parkhurst.

The conception of life as the basis for a thesis was first suggested to me at Wellesley College by Professors Mary W. Calkins and Mary S. Case and it was under their direction that I began the study of it. My conclusions at that time were embodied in a thesis, entitled "A Conception of Life," offered in partial fulfilment of the requirements for a master's degręe at Wellesley in November 1914. The subject still fascinated me and in 1919, with the encouragement of Professor W. P. Montague and the permission of the Graduate Council at Wellesley College, I decided to continue with it for a doctor's dissertation. The final work was done upon it under the direction of Professor F. J. E. Woodbridge. 


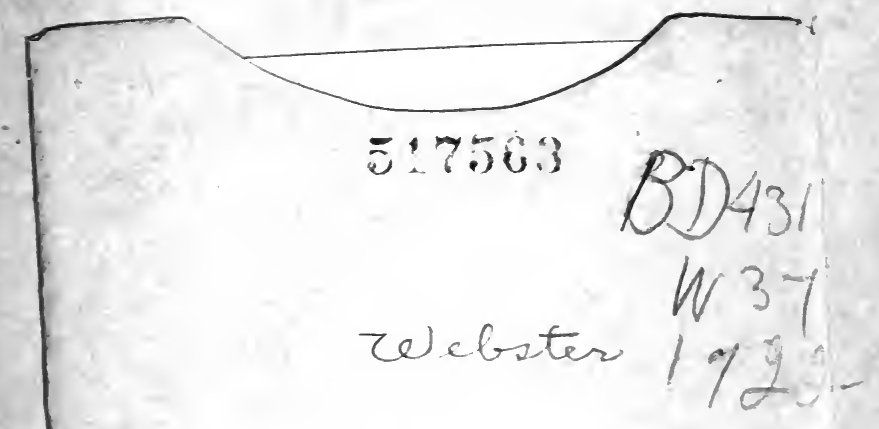

- UNIVERSITY OF CALIFORNIA LIBRARY

\section{UNIVERSITY OF CALIFORNIA LIBRARY BERKELEY}

Return to desk from which borrowed.

This book is DUE on the last date stamped below. 
